\title{
Effects of Large Volcanic Eruptions on Global Summer Climate and East Asian Monsoon Changes during the Last Millennium: Analysis of MPI-ESM Simulations
}

\author{
WENMIN MAN \\ LASG, Institute of Atmospheric Physics, Chinese Academy of Sciences, Beijing, China
}

TIANJUN ZHOU

LASG, Institute of Atmospheric Physics, and Climate Change Research Center, Chinese Academy of Sciences, Beijing, China

\author{
JOHANN H. JUNGCLAUS
}

Max Planck Institute for Meteorology, Hamburg, Germany

(Manuscript received 3 December 2013, in final form 18 June 2014)

\begin{abstract}
Responses of summer [June-August (JJA)] temperature and precipitation to large volcanic eruptions are analyzed using the millennial simulations of the earth system model developed at the Max Planck Institute for Meteorology. The model was driven by up-to-date reconstructions of external forcing, including natural forcing (solar and volcanic) and anthropogenic forcing (land-cover change and greenhouse gases). Cooling anomalies after large volcanic eruptions are seen on a nearly global scale. The cooling in the Northern Hemisphere (NH) is stronger than in the Southern Hemisphere ( $\mathrm{SH}$ ), and cooling is stronger over the continents than over the oceans. The precipitation decreases in the tropical and subtropical regions in the first summer after large volcanic eruptions. The cooling, with amplitudes of up to $-0.6^{\circ} \mathrm{C}$, is also seen over eastern China. East Asia is dominated by northerly wind anomalies, and the corresponding summer rainfall exhibits a coherent reduction over the entirety of eastern China. The tropospheric mean temperature anomalies indicate that there is coherent cooling over East Asia and the tropical ocean after large volcanic eruptions. The cooling over the middle-to-high latitudes of East Asia is stronger than over the tropical ocean. This temperature anomaly pattern suggests a reduced land-sea thermal contrast and favors a weaker East Asian summer monsoon (EASM) circulation. Analysis of the radiative fluxes at the top of the atmosphere (TOA) suggests that the reduction in shortwave radiation after large volcanic eruptions is nearly twice as large as the reduction in emitted longwave radiation, a net loss of radiative energy that cools the surface and lower troposphere.
\end{abstract}

\section{Introduction}

Volcanic eruptions provide a valuable opportunity to observe the climate system's response to the presence of an external radiative forcing (Hansen et al. 1992; Kirchner et al. 1999; Robock 2000). Strong volcanic eruptions inject large amounts of sulfur dioxide into the lower stratosphere and form aerosol particles. Winds rapidly disperse the particles throughout the lower stratosphere, resulting

Corresponding author address: Dr. Tianjun Zhou, LASG, Institute of Atmospheric Physics, Chinese Academy of Sciences, Hua YanLi No. 40, QiJiaHuozi, Chaoyang District, Beijing 100029, China.

E-mail: zhoutj@lasg.iap.ac.cn in a near-global perturbation to the radiative energy balance. Since the scattering of incoming solar radiation by aerosol particles produces an increase of the fraction of solar radiation scattered back to space and, hence, a decrease of the fraction reaching Earth's surface (Dutton and Christy 1992; Crowley et al. 1993), the net radiative effect of the volcanic aerosols is to cool the planet. The eruption of Mount Pinatubo in the Philippines in June 1991 resulted in a significant decrease in solar heating due to the stratospheric aerosol particles (Stowe et al. 1992; Trepte et al. 1993; Minnis et al. 1993), which led to a global cooling of the lower troposphere (Robock and Mao 1992).

Previous studies have detected the influence of volcanic forcing on temperature on a global scale (Mitchell 
et al. 2001). However, precipitation changes are likely to have more direct impacts on society and the environment. Thus, whether there has been a detectable influence of volcanic forcing on precipitation should receive more attention. Allen and Ingram (2002) demonstrated that the influence of external forcing was detectable in terrestrial precipitation. Lambert et al. (2004) attribute the response of land precipitation to changes in shortwave forcing rather than to longwave forcing. Broccoli et al. (2003) found that simulations of the Geophysical Fluid Dynamics Laboratory (GFDL) coupled model forced with greenhouse gas changes only were unable to reproduce observed precipitation trends, but in simulations including volcanic aerosol, they found a decrease in precipitation following the Pinatubo eruption similar to that observed. A detection and attribution analysis applied to the precipitation also indicated that the volcanic signal was detectable by regressing the observed precipitation against only the volcanic forcing and in a multiple regression with other forcings (Gillett et al. 2004). These results are consistent with the hypothesis that shortwave forcings exert a larger influence on precipitation than do longwave forcings. Trenberth and Dai (2007) examined the hydrological cycle for the effects of volcanic eruptions from El Chichón in March 1982 and Pinatubo in June 1991, taking into account changes from the El Niño-Southern Oscillation (ENSO). Following the eruption of Mount Pinatubo in June 1991, there was a substantial decrease in precipitation over land and a record decrease in runoff and river discharge into the ocean. A number of authors also looked at the monsoon impacts from volcanic eruptions, and these studies indicated that volcanic eruptions could weaken the summer monsoon circulations, including the African, Indian, and Asian monsoon systems (Graf 1992; Oman et al. 2006; Peng et al. 2010). Several state-of-the-art general circulation model (GCM) simulations (Oman et al. 2005; Schneider et al. 2009; Fan et al. 2009) predict drought conditions over monsoon Asia in response to large tropical and extratropical eruptions. Anchukaitis et al. (2010) examined the influence of major volcanic eruptions on the climate of Asia by using the proxy drought reconstructions and revealed significantly wetter conditions over mainland Southeast Asia in the year of an eruption, with drier conditions in central Asia. The proxy and model comparison suggested that GCMs may not capture all of the important ocean-atmosphere dynamics responsible for the influence of explosive volcanism on the climate of Asia.

The summer precipitation of eastern China is also affected by volcanic forcing (Zhang and Zhang 1994; Gong and Wang 2000; Bradbury 2006; Shen et al. 2007, 2008). Based on the data network of the dryness/wetness index (DWI) over eastern China, Shen et al. (2008) showed that the high occurrence frequency of anomalous precipitation events mainly occurred at periods of high solar forcing, active volcanic eruption, and large anthropogenic forcing. Coherence (coherent floods/ droughts) and dipole were the two dominant modes in spatial patterns of anomalous precipitation events. The results further indicated that the dominant spatial patterns of anomalous precipitation events associated with large low-latitude volcanic eruptions were coherent droughts. Previous studies also indicated that volcanic eruptions could cause cool summers (Robock and Mao 1992) and more snow cover on the Eurasian continent (Robock 2002), weakening the strength of the summer monsoon (Hahn and Shukla 1976; Tao et al. 1988; Liu and Yanai 2002; Fasullo 2004). Lower temperatures in summer may enhance the high ridge or blocking situation over eastern Siberia, which makes the subtropical high shift farther south (Ding 1992). Xu (1986) investigated the impacts of three colossal volcanic eruptions on summer rainfall in China. He found that significant reductions of shortwave radiation occurred in the summers of 1965, 1975, and 1980 over eastern China, when northern China experienced moderate (1975) to severe droughts (1965 and 1980). He attributed this anomalous summer rainfall to the southward shift of the subtropical high and the monsoon rainfall belt due to the anomalous decline of shortwave radiation.

Climate models are useful tools in understanding the climate effects of volcanism during the last millennium. In earlier studies, the effect of volcanism was simply applied as the reduction of global solar irradiance (Peng et al. 2010). The seasonal and latitudinal dependence of volcanic aerosol, as well as the stratospheric warming by volcanic eruptions, were not taken into account. However, the climatic processes of volcanic eruptions are much more complicated than in the earlier treatments, which simply implemented the effect of volcanic eruption as a negative deviation from the solar radiation. Thus, the simulations driven by the monthly and latitudinally varying volcanic aerosol dataset were conducted for a more realistic understanding of the effects of volcanic aerosol on global climate during the last millennium (Ammann et al. 2007; Jungclaus et al. 2010; Schmidt et al. 2014; Phipps et al. 2012; Landrum et al. 2013). The present study aims to examine the responses of the global summer [June-August (JJA)] climate and East Asian summer monsoon (EASM) to large volcanic eruptions during the last millennium by analyzing the ensemble climate simulations carried out with the comprehensive Max Planck Institute (MPI) Earth System Model (MPI-ESM; Jungclaus et al. 2010). It should 
be made clear that these are not new simulations carried out with the existing model. The centennial-scale variations of the EASM and the associated rainfall patterns during the last millennium have been analyzed using these simulations (Man et al. 2012). The MPI-ESM has also been applied successfully for volcano studies (Timmreck et al. 2009, 2010), as well as in studies of the decadal climate response to large tropical volcanic eruptions (Zanchettin et al. 2012, 2013), and the impacts and cooperative effects of volcanic eruptions and ENSO (Zhang et al. 2013). The main motivation of this study is to answer the following questions: 1 ) What is the level of consistency between the simulated and observed summer temperature and precipitation responses to three large volcanic eruptions (Agung in 1963, El Chichón in 1982, and Mount Pinatubo in 1991)? 2) What are the simulated responses of global summer temperature and precipitation to large volcanic eruptions during the last millennium? 3) What are the simulated responses of EASM to large volcanic eruptions during the last millennium, and does the reasonable treatment of the seasonal and latitudinal dependence of volcanic aerosol in MPI-ESM result in a different response of EASM in comparison with previous studies? 4) What is the dominant reason for the simulated monsoon and precipitation changes over East Asia after large volcanic eruptions?

The remainder of the paper is organized as follows. Section 2 provides a description of the model and the experimental design, as well as the details of external forcings used in the simulations. Section 3 presents the results. The conclusions are given in section 4 .

\section{Model and data description}

\section{a. Model description}

The experiments have been performed with the MPIESM (Jungclaus et al. 2010). The model consists of the atmospheric general circulation model ECHAM5 (Roeckner et al. 2003), the MPI Ocean Model (MPIOM; Marsland et al. 2003). Modules for land vegetation [the Jena Scheme for Biosphere-Atmosphere Coupling in Hamburg (JSBACH; Raddatz et al. 2007)] and ocean biogeochemistry [the Hamburg Model of the Ocean Carbon Cycle (HAMOCC; Wetzel et al. 2006)] enable the interactive simulation of the carbon cycle. ECHAM5 is run at $\mathrm{T} 31$ spectral resolution $\left(\sim 3.75^{\circ}\right)$ with 19 vertical levels, resolving the atmosphere up to $10 \mathrm{hPa}$. MPI-OM applies a conformal mapping grid with a horizontal resolution ranging from 22 to $350 \mathrm{~km}$. The ocean model includes a Hibler-type dynamic-thermodynamic sea ice model with viscous-plastic rheology (Hibler 1979). Ocean and atmosphere are coupled daily without flux corrections using the Ocean Atmosphere Sea Ice Soil, version 3 (OASIS3) coupler (Valcke et al. 2003).

\section{b. Forcing data}

The simulations include the following climate forcing: the solar irradiance that exhibits a total increase of $0.1 \%$ $\left(\sim 1.3 \mathrm{~W} \mathrm{~m}^{-2}\right)$ from the Maunder Minimum (AD 16471715) to today (Vieira et al. 2011); the volcanic forcing that is calculated online using a time series of aerosol optical depth and of the effective radius (Crowley et al. 2008; Timmreck et al. 2009); and the anthropogenic land cover change that is considered by applying the reconstruction of global agricultural areas and land cover (Pongratz et al. 2008). The $\mathrm{CO}_{2}$ concentration is calculated interactively within the model, while the concentrations of methane $\left(\mathrm{CH}_{4}\right)$ and nitrous oxide $\left(\mathrm{N}_{2} \mathrm{O}\right)$ are prescribed (Macfarling Meure et al. 2006). The orbital forcing and anthropogenic tropospheric sulfate aerosols are also included in the ensemble experiments [see Jungclaus et al. (2010) for details]. Starting from different ocean initial conditions, a five-member ensemble with the standard external forcing spanning the years AD 800-2005 was conducted using the MPI-ESM. The ensemble mean of the five realizations is used in the following analysis.

\section{c. Analysis method}

The volcanic forcing is represented in terms of the aerosol optical depth and the effective radius distribution (Crowley et al. 2008). In the simulation, this forcing is resolved in four latitude bands $\left(30^{\circ}-90^{\circ} \mathrm{N}, 0^{\circ}-30^{\circ} \mathrm{N}\right.$, $0^{\circ}-30^{\circ} \mathrm{S}$, and $30^{\circ}-90^{\circ} \mathrm{S}$ ) with a temporal resolution of 10 days (Jungclaus et al. 2010). In the annual forcing series, large volcanic eruptions are defined as those with the strongest reduction in net top solar radiation of $2 \mathrm{~W} \mathrm{~m}^{-2}$ or more [for details, see Zhang et al. (2013)] (Table 1). The lowest reduction in this set is $-2.0 \mathrm{~W} \mathrm{~m}^{-2}$ from Santa Maria in Guatemala in 1903, which was slightly larger than $-1.7 \mathrm{~W} \mathrm{~m}^{-2}$, according to observations. The 1258 giant volcanic eruption (unknown volcano) causes a maximum reduction of radiation between -16.4 and $-16.9 \mathrm{~W} \mathrm{~m}^{-2}$ in all five ensemble members. As in Peng et al. (2010), the year with the largest reduction in irradiance is defined as the volcanic eruption year. However, the model may have a delayed response to the event year because of the aerosol layer accumulation, which could lead to a discrepancy between the historic and simulated eruption years.

In previous studies (Adams et al. 2003; Shen et al. 2008; Peng et al. 2010), the anomalies were calculated relative to the five prevolcanic eruption, eruption, and five postvolcanic eruption years that included the event 
TABLE 1. List of the selected 21 volcanic eruptions between 800 and 2005 (eruption year is defined by a decrease in net top solar irradiation of at least $-2.0 \mathrm{~W} \mathrm{~m}^{-2}$ ). The volcanic explosivity index (VEI) is included and boldface table entries indicate data uncertainty (Newhall and Self 1982; Global Volcanism Program, Smithsonian National Museum of Natural History, Washington, D.C.).

\begin{tabular}{rrcc}
\hline \hline No. & Year & Name & VEI \\
\hline 1 & 842 & Unknown & - \\
2 & 854 & Unknown & - \\
3 & 897 & Unknown & - \\
4 & 971 & Unknown & - \\
5 & 1193 & Unknown & - \\
6 & 1228 & Unknown & - \\
7 & 1258 & Unknown & - \\
8 & 1286 & Unknown & - \\
9 & 1442 & Unknown & - \\
10 & 1456 & Pinatubo & 6 \\
11 & 1600 & Huaynaputina & 6 \\
12 & 1641 & Parker & 6 \\
13 & 1673 & Capelo & - \\
14 & 1694 & Serua/Helka & - \\
15 & 1809 & St. Helens & - \\
16 & 1815 & Tambora & 7 \\
17 & 1832 & Babuyan Claro & $\mathbf{4}$ \\
18 & 1835 & Cosigulna & - \\
19 & 1884 & Krakatau & 6 \\
20 & 1903 & Grimsvotn & 4 \\
21 & 1992 & Pinatubo & 6 \\
\hline
\end{tabular}

year and the years after the eruption in the climatology. However, in doing this, at least 3 of the 11 climatological years (years 0,1 , and 2) have significant volcanic-induced signals. This has multiple ramifications, including decreasing the mean temperature and precipitation of the climatology and increasing the standard deviation of the climatology. Thus, in the following discussions, the climatology is calculated by taking the prior five years, skipping the volcanic eruption year and two years after, and then using the next five years.

\section{d. Reanalysis data}

The datasets used for validation of the model performance are as follows:

1) The Goddard Institute for Space Studies (GISS) Surface Temperature Analysis (GISTEMP) dataset derived from the adjusted Global Historical Climatology Network (GHCN), version 3, data for the period since 1880 on a $2.0^{\circ} \times 2.0^{\circ}$ grid (Hansen et al. 2010);

2) The Precipitation Reconstruction Dataset (PREC) from the National Oceanic and Atmospheric Administration (NOAA) for the period of 1948-2005 on a $2.5^{\circ} \times 2.5^{\circ}$ grid (Chen et al. 2002).

3) The 753-station temperature and precipitation dataset for the period of 1958-2005 from the China Meteorological Administration (CMA).

\section{Results}

First, we present the global surface air temperature (SAT) and rainfall distribution in the first summer after three large volcanic eruptions (Agung in 1963, El Chichón in 1982, and Mount Pinatubo in 1991) based on the observational dataset for model validation. Then, we focus on the global summer climate and the monsoonal circulation and precipitation changes after large volcanic eruptions during the last millennium. Finally, we try to attribute the underlying causes of the EASM responses to large volcanic eruptions from the perspective of landsea thermal contrast.

\section{a. Temperature and precipitation responses for the observed cases}

The observed and simulated patterns of SAT anomalies in the first summer after the Agung, El Chichón, and Mount Pinatubo eruptions are shown in Fig. 1. The observations show a general cooling with a magnitude of about $-0.4^{\circ} \mathrm{C}$ over the landmasses in the Northern Hemisphere (NH) in the first summer after the Agung eruption, except for parts of western and northern Europe and southern North America (Fig. 1a). The cooling in the Southern Hemisphere $(\mathrm{SH})$ is significant over southern Africa and east of South America. The model reproduces the overall summer cooling pattern after the Agung eruption (Fig. 1b). The observed significant cooling anomalies over southern Africa and South America are reasonably reproduced in the model. The model simulates significant cooling anomalies in Australia, which is opposite of the observational data. The simulated cooling anomalies in the SH are more significant than those in the $\mathrm{NH}$, which indicates that the Agung aerosols largely impact the $\mathrm{SH}$, with less impact in the NH. The aerosol loading also suggests that a larger part of aerosols locate in the SH (especially in $20^{\circ}-60^{\circ} \mathrm{S}$ ) in the first summer after the Agung eruption. The summer cooling after the 1982 El Chichón eruption is not as evident as the cooling after the Agung eruption in both the observations and the simulation (Figs. 1c,d). The observation shows an overall cooling with an amplitude of about $-0.6^{\circ} \mathrm{C}$ in the first summer after the Pinatubo eruption (Fig. 1e). There is a significant warming in the eastern tropical Pacific Ocean, and this year also corresponds to a persistent El Niño. The warming is not reproduced by the model, which instead shows a significant cooling pattern over this region (Fig. 1f). As in the observations, the significant cooling anomalies are enhanced over North America and Eurasia in the simulation; however, the magnitude of the simulated cooling (with a value of about $-0.4^{\circ} \mathrm{C}$ ) is slightly weaker compared with the observations. 
(a) GISTEMP

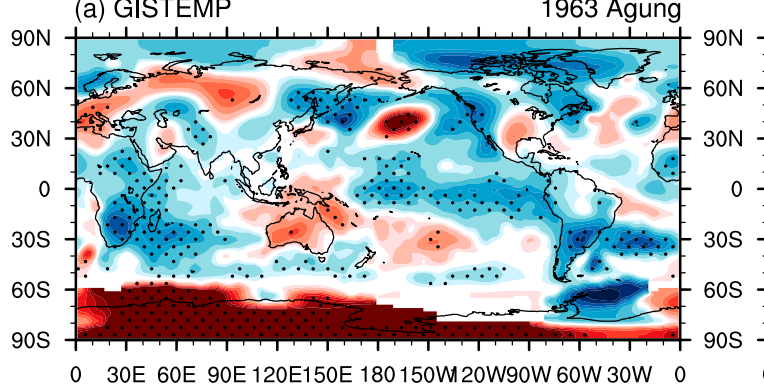

(c) GISTEMP

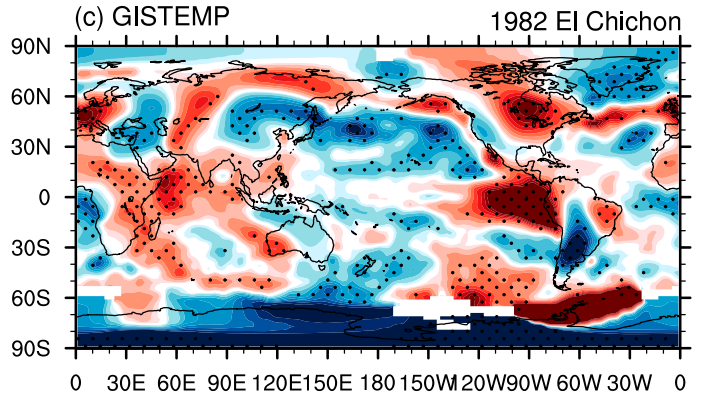

(e) GISTEMP

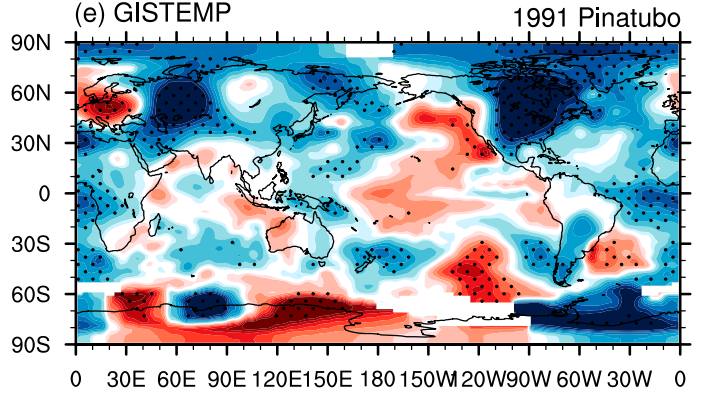

(b) MPI-ESM
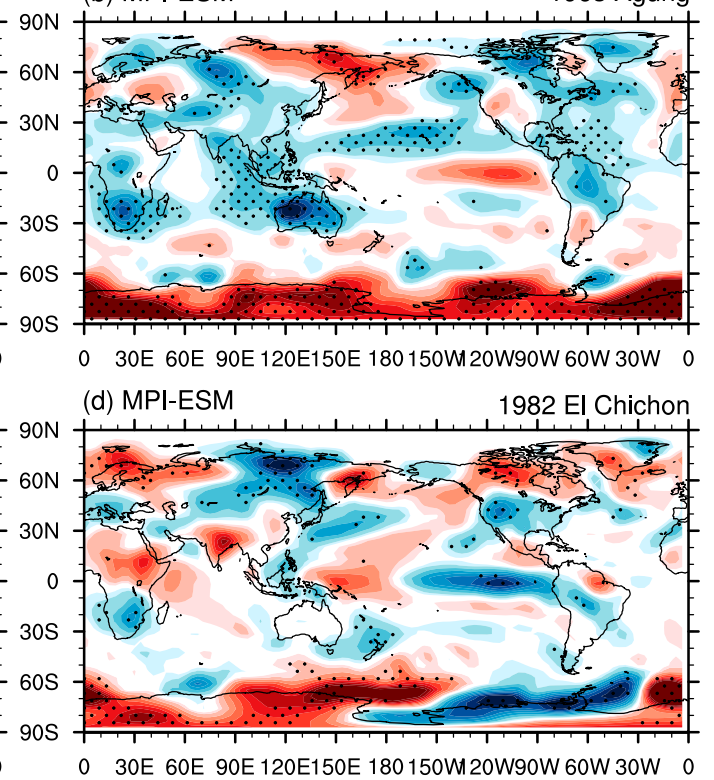

(d) MPI-ESM
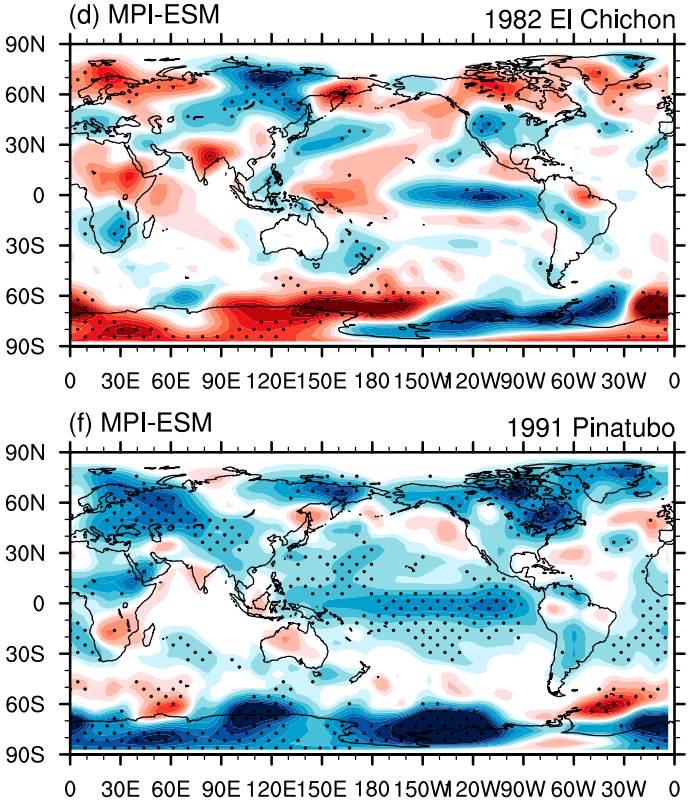

(f) MPI-ESM

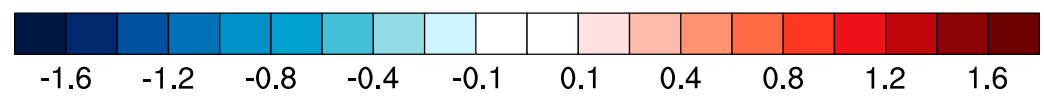

FIG. 1. Spatial patterns of global SAT anomalies $\left({ }^{\circ} \mathrm{C}\right)$ in the first summer (JJA) after the eruptions of (a),(b) Agung, (c),(d) El Chichón, and (e),(f) Pinatubo for (left) the observations (based on GISTEMP) and (right) the MPI-ESM simulation. The climatology is calculated by taking the prior $5 \mathrm{yr}$, skipping the volcanic eruption year and $2 \mathrm{yr}$ after, and then using the next $5 \mathrm{yr}$. The regions shaded by black dots denote areas that are significant at the $5 \%$ level based on the statistical test on the assumption of normal distribution.

The observed and simulated patterns of precipitation anomalies in the first summer after the three volcanic eruptions are shown in Fig. 2. Besides the tropical western Pacific, southern North America, and parts of the North Pacific, most of the significant negative precipitation anomalies are seen in the $\mathrm{SH}$ in the first summer after the Agung eruption in the observations (Fig. 2a). The simulation exhibits significant negative precipitation anomalies in the tropical Indian Ocean (Fig. 2b). The simulated negative precipitation anomalies in the $\mathrm{SH}$ are comparable to those in the observations. This further indicates that the Agung aerosols impact more in the SH than in the NH. The observations exhibit significant negative precipitation anomalies in the highlatitude European continent and North America in the first summer after the El Chichón eruption (Fig. 2c), which are not evident in the simulation (Fig. 2d). Parts of the regions in the $\mathrm{SH}$ are characterized by significant negative precipitation anomalies in both the observations and the simulation. In the first summer after the Pinatubo eruption (Fig. 2e), the precipitation shows significant negative anomalies in the tropical Atlantic Ocean and the Maritime Continent regions, with a maximum of the negative anomalies of up to $-1.5 \mathrm{~mm}_{\text {day }}{ }^{-1}$. The Eurasian Arctic and the high latitudes of North America also feature negative precipitation anomalies. Significant positive precipitation anomalies are seen in the tropical Pacific Ocean in the observations. In the simulation (Fig. 2f), the precipitation features significant negative anomalies in the tropical and extratropical 
(a) PREC

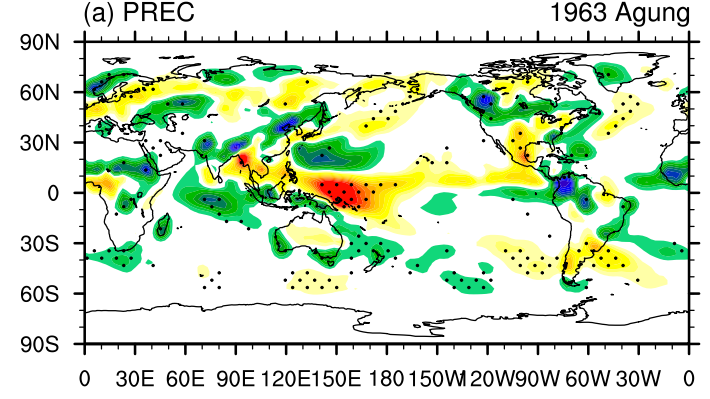

(c) PREC

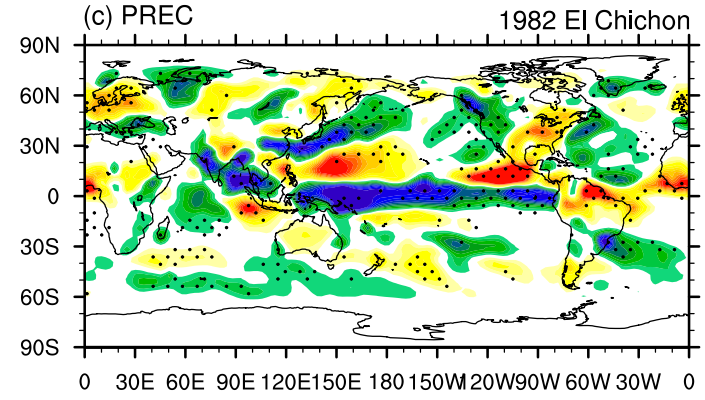

(e) PREC

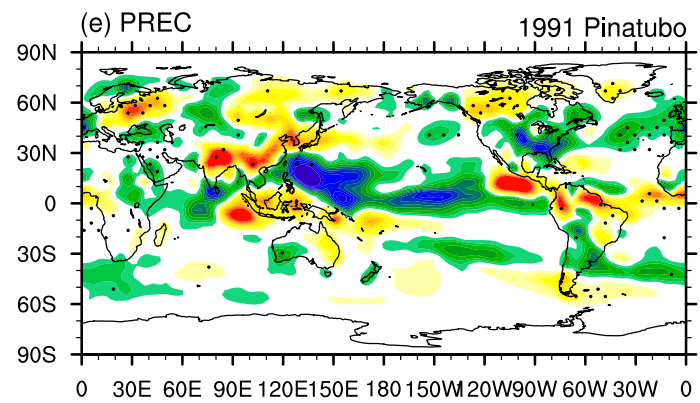

(b) MPI-ESM

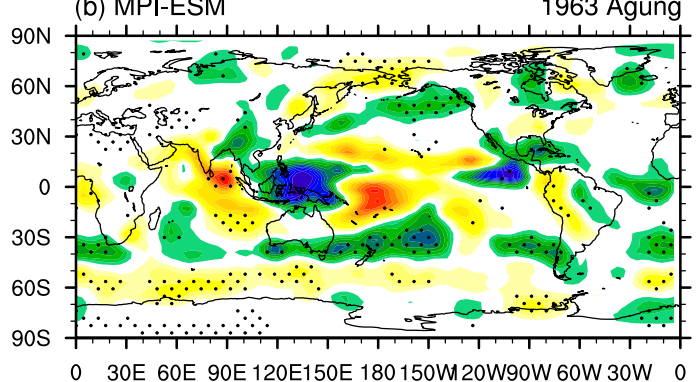

(d) MPI-ESM

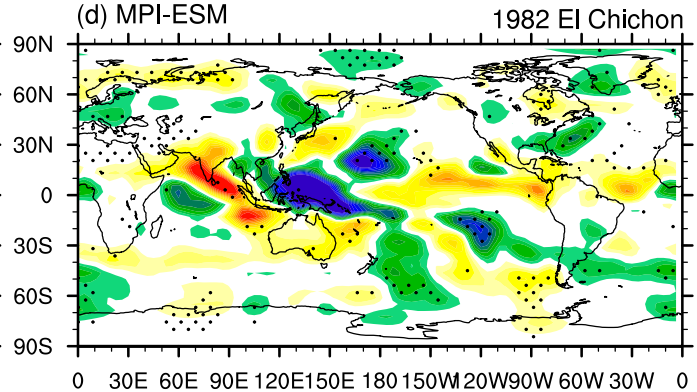

0 30E 60E 90E 120E150E 180150 W20W90W 60W 30W 0

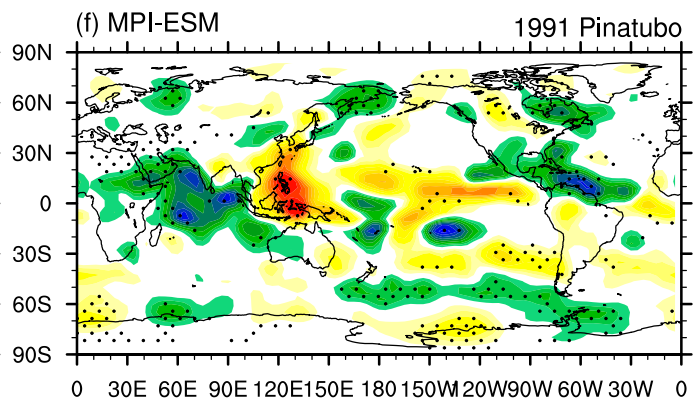

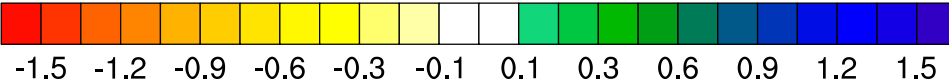

FIG. 2. Spatial patterns of global precipitation anomalies $\left(\mathrm{mm} \mathrm{day}^{-1}\right)$ in the first summer after the eruptions of (a),(b) Agung, (c),(d) El Chichón, and (e),(f) Pinatubo for (left) the observations (based on PREC) and (right) the MPI-ESM simulation. The climatology is calculated by taking the prior $5 \mathrm{yr}$, skipping the volcanic eruption year and $2 \mathrm{yr}$ after, and then using the next $5 \mathrm{yr}$. The regions shaded by black dots denote areas that are significant at the $5 \%$ level based on the statistical test on the assumption of normal distribution.

Pacific Ocean as well as in the Maritime Continent region. The differences in the observed and simulated tropical SST patterns lead to the large discrepancy in the tropical Pacific Ocean precipitation anomalies between the simulation and the observations (not shown). It should also be noted that there are significant positive precipitation anomalies in the Caribbean after the 1963 Agung eruption and the 1991 Pinatubo eruption in the simulation, which may be due to the significant convergence of the anomalous water vapor transport after both eruptions.

The observed and simulated patterns of SAT anomalies over China in the first summer after the three volcanic eruptions are further shown in Fig. 3. The observed patterns are from the 753-station temperature dataset of CMA. The observations show a significant cooling pattern over China in the first summer after the Agung eruption, except for parts of northwest and southwest China (Fig. 3a). Cooling anomalies with amplitudes between -0.2 and $-0.4^{\circ} \mathrm{C}$ are seen over the whole of China in the simulation (Fig. 3b). There are significant cooling anomalies with amplitudes of up to $-0.8^{\circ} \mathrm{C}$ over central China in the first summer after the El Chichón eruption, while warming anomalies are seen in south and north China (Fig. 3c). The pattern of the simulated SAT anomalies corresponds well with that of the observation; however, the amplitude of the cooling anomalies over central China $\left(-0.2^{\circ} \mathrm{C}\right)$ is much weaker than in the observations (Fig. 3d). The observations show an overall cooling pattern with an amplitude of about $-0.6^{\circ} \mathrm{C}$ after the Pinatubo eruption, except for 
(a) Obs

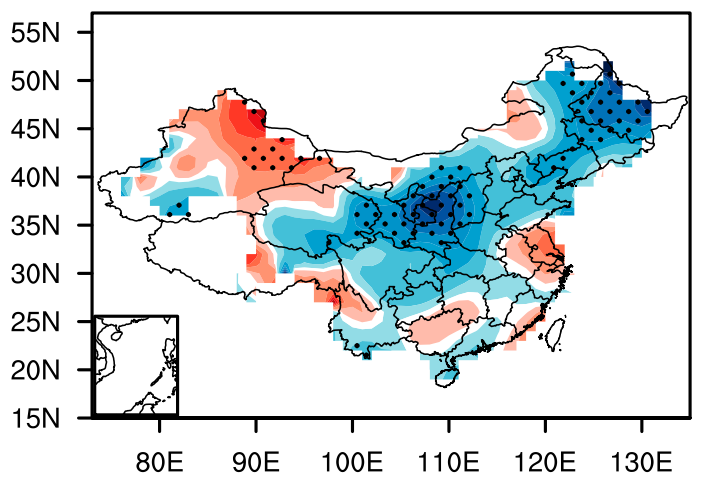

(c) Obs

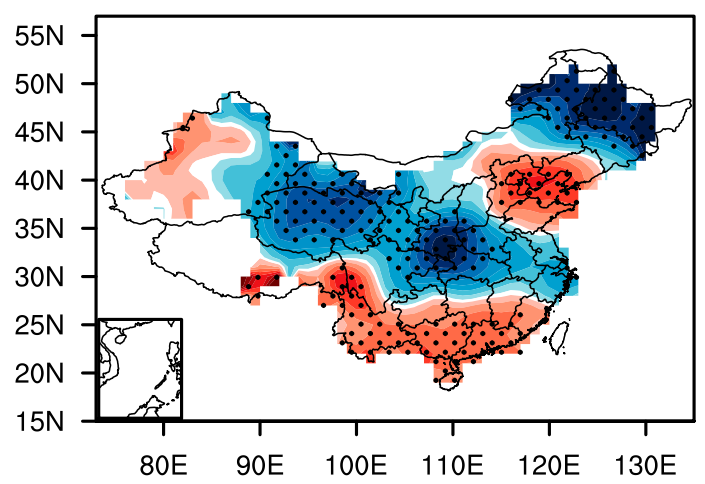

(e) Obs

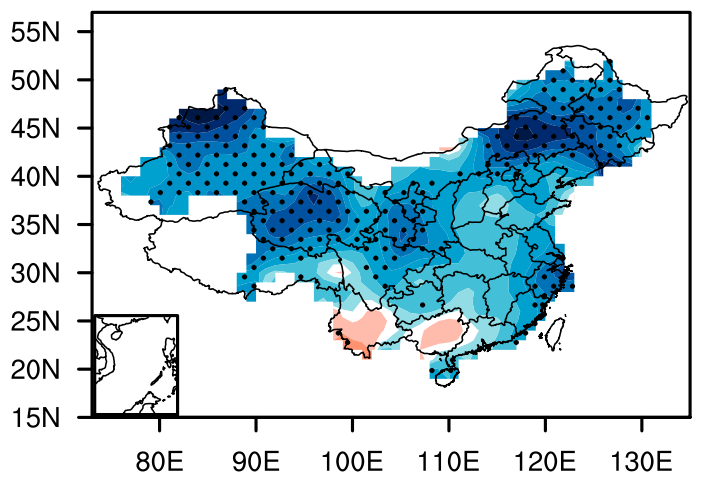

(b) MPI-ESM 1963 Agung

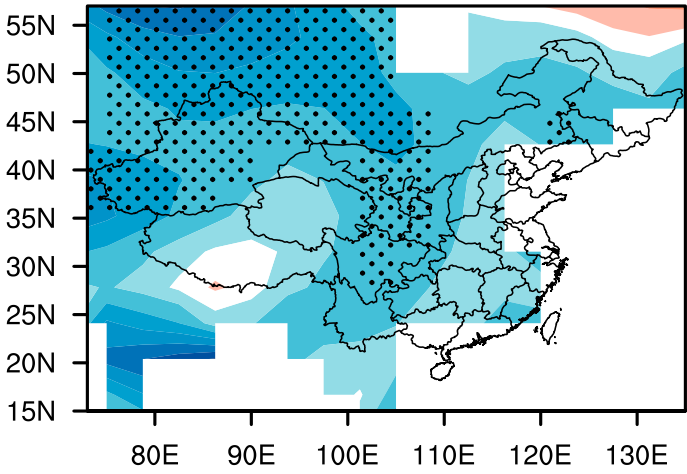

(d) MPI-ESM

1982 El Chichon

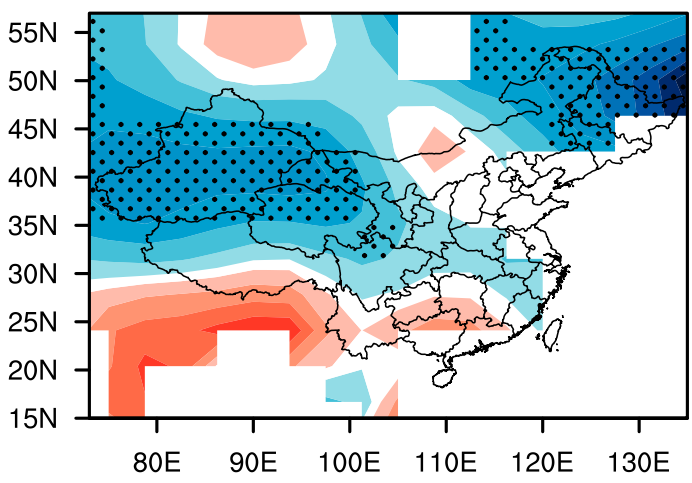

(f) MPI-ESM

1991 Pinatubo

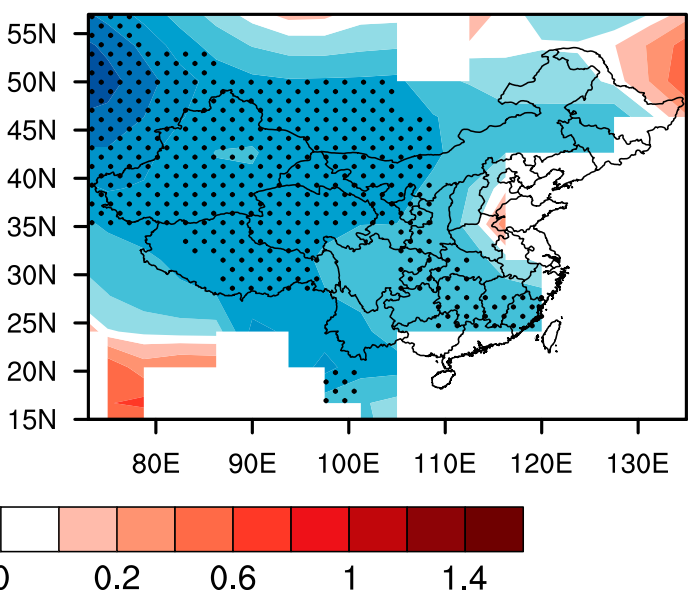

FIG. 3. Spatial patterns of SAT anomalies $\left({ }^{\circ} \mathrm{C}\right)$ over China in the first summer after the eruptions of (a),(b) Agung, (c),(d) El Chichón, and (e),(f) Pinatubo for (left) the observations (based on the 753-station dataset from the Chinese Meteorological Administration) and (right) the MPI-ESM simulation. The climatology is calculated by taking the prior $5 \mathrm{yr}$, skipping the volcanic eruption yr and $2 \mathrm{yr}$ after, and then using the next $5 \mathrm{yr}$. The regions shaded by black dots denote areas that are significant at the $5 \%$ level based on the statistical test on the assumption of normal distribution.

slight warming anomalies in southwestern China (Fig. 3e). Consistent cooling anomalies are seen after the Pinatubo eruption in the simulation (Fig. 3f). The pattern correlations of the observed and simulated SAT patterns over
China in the first summer after the three volcanic eruptions are $0.4,0.48$, and 0.55 , respectively.

The precipitation anomalies over China in the first summer after the Agung, El Chichón, and Mount Pinatubo 
(a) Obs

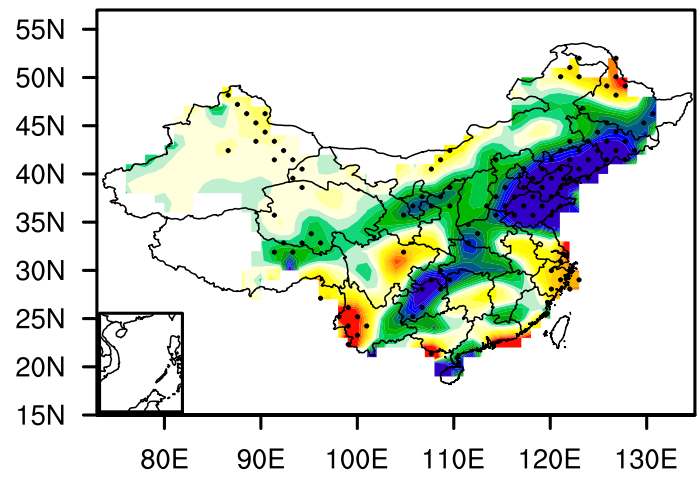

(c) Obs

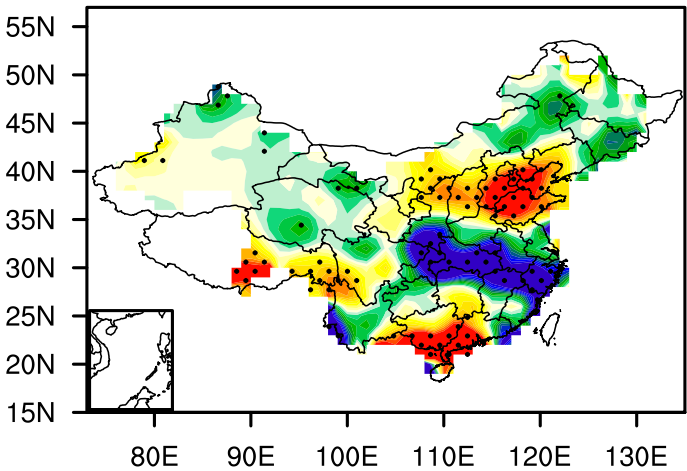

(e) Obs

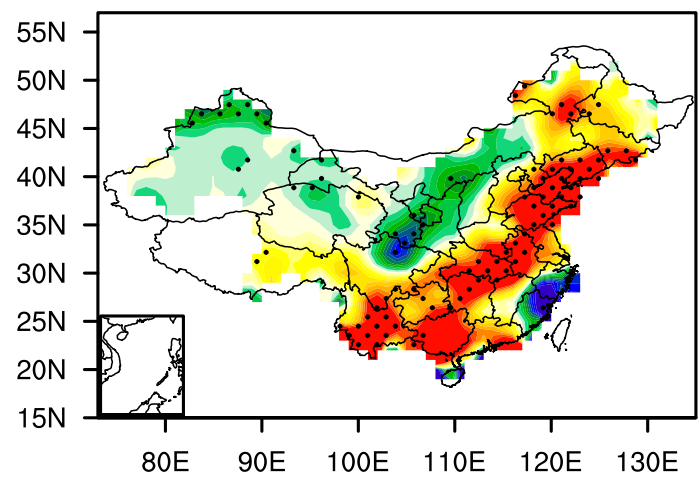

(b) MPI-ESM

1963 Agung

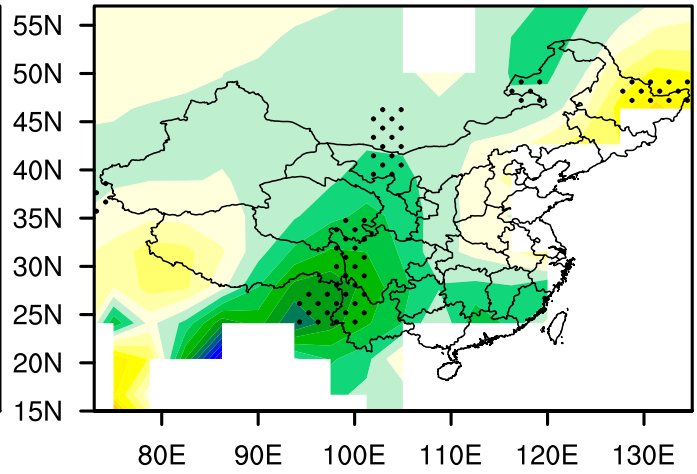

(d) MPI-ESM

1982 El Chichon

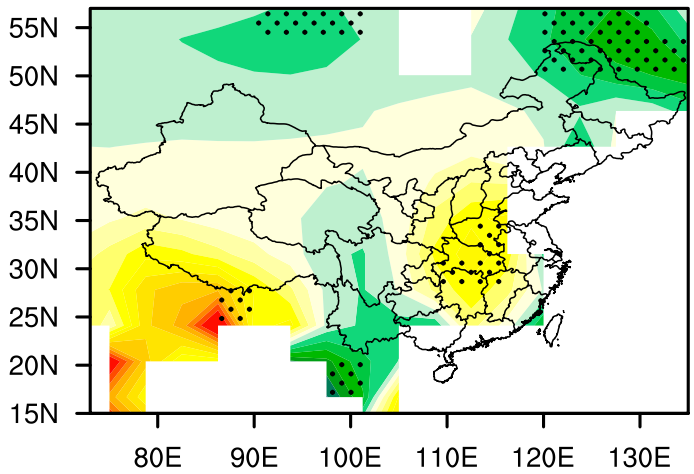

(f) MPI-ESM
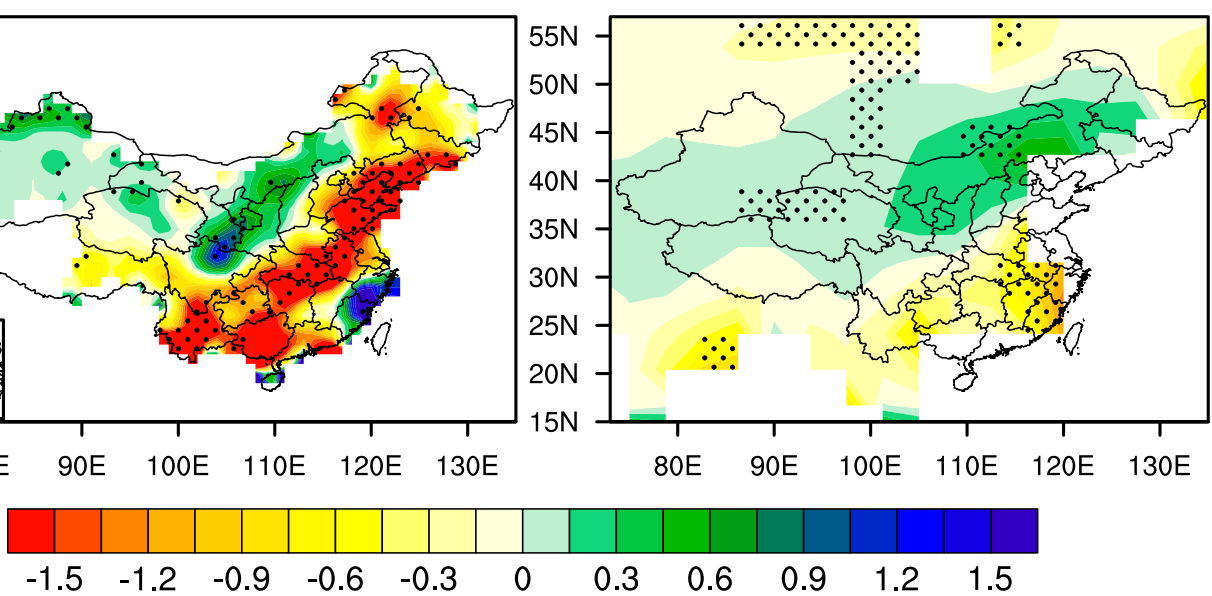

FIG. 4. Spatial patterns of summer precipitation anomalies $\left(\mathrm{mm} \mathrm{day}^{-1}\right)$ over China in the first summer after the eruptions of (a),(b) Agung, (c),(d) El Chichón, and (e),(f) Pinatubo for (left) the observations (based on the 753station dataset from the Chinese Meteorological Administration) and (right) the MPI-ESM simulation. The climatologies are calculated by taking the prior $5 \mathrm{yr}$, skipping the volcanic eruption $\mathrm{yr}$ and $2 \mathrm{yr}$ after, and then using the next $5 \mathrm{yr}$. The regions shaded by black dots denote areas that are significant at the $5 \%$ level based on the statistical test on the assumption of normal distribution.

eruptions are shown in Fig. 4. The observed precipitation anomaly patterns are from the 753-station dataset of CMA. The observed precipitation decreases in southern China and the lower Yangtze River valley but increases over northern China in the first summer after the Agung eruption (Fig. 4a). The simulated precipitation anomalies over eastern China show a large discrepancy with the observations (Fig. 4b). Deficient precipitation is evident over northern China, while excessive precipitation is seen south of the Yangtze River valley. The anomalies of precipitation 
exhibit a meridional tripolar pattern in the observations in the first summer after the El Chichón eruption (Fig. 4c). Deficient precipitation is evident over northern and southern China, while excessive precipitation is seen along the Yangtze River valley. While the rainfall anomalies exhibit a coherent reduction over eastern China in the simulation (Fig. 4d). The observed precipitation anomalies decrease over eastern China, except for the southeast coastal area, in the first summer after the Pinatubo eruption (Fig. 4e). However, the simulated precipitation anomalies exhibit drought in central and south China and excessive rainfall in north China (Fig. 4f). To explain the large discrepancy between the simulated and the observed precipitation anomalies over eastern China, the tropical sea surface temperature (SST) patterns, which may be dominant in this region, are compared (not shown). The observations show strong El Niño phases after the eruptions of El Chichón and Pinatubo, while the model fails to reproduce the positive eastern tropical Pacific SST anomalies, although an increase of the probability of El Niño events after volcanic eruptions is detected in reconstructions (Adams et al. 2003). The different ENSO state could be highly relevant for the discrepancy between the simulated and the observed rainfall patterns over eastern China.

Overall, the model has a certain ability to reproduce the responses of summer temperatures and precipitation to volcanic eruptions based on the observations, but there are also strong dissimilarities between the simulation and the observations. The differences of the ENSO state may, in part, determine the discrepancies between the simulated and the observed temperature and precipitation anomalies, especially in the region of East Asia. The faithful verification of the model's performance provides a foundation for the following analysis.

\section{b. Temperature and precipitation responses to the 21 cases of large volcanic eruptions}

To determine the presence or absence of a volcanic forcing signal, we conducted a superposed epoch analysis (SEA; Haurwitz and Brier 1981) to assess if there is a statistically significant reduction in summer temperature and precipitation during and after the volcanic eruption years. The SEA results of global-mean summer SAT and precipitation anomalies for the 21 cases of large volcanic eruptions in the five prevolcanic eruption years, volcanic eruption year, and five postvolcanic eruption years are shown in Fig. 5. There is a peak global cooling during the volcanic eruption year and two years after, after which the SAT slowly returns to preeruption levels (Fig. 5a). The largest reduction of the SAT anomalies appears in the year after the volcanic eruption. The precipitation also significantly decreases during
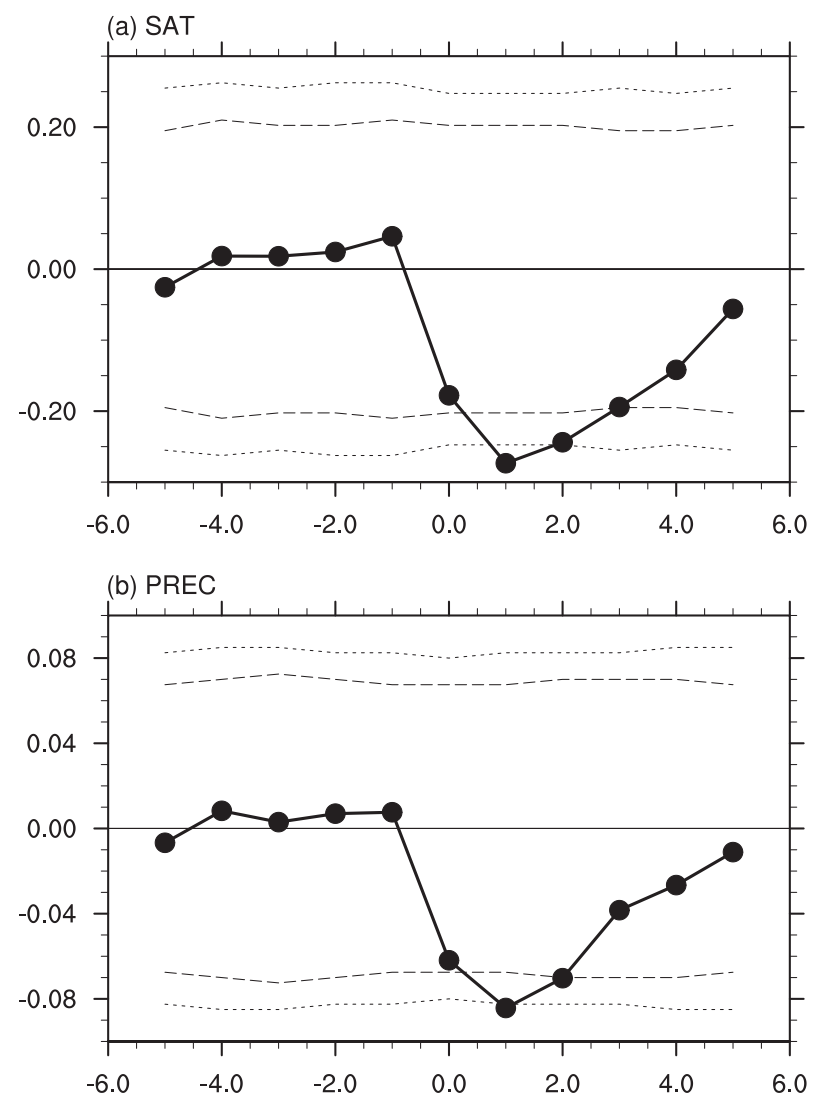

FIG. 5. SEA of global-mean summer (a) SAT $\left({ }^{\circ} \mathrm{C}\right)$ and (b) precipitation $\left(\mathrm{mm} \mathrm{day}^{-1}\right)$ for the 21 cases of large volcanic eruptions in the 5 prevolcanic eruption years, the volcanic eruption year, and the 5 postvolcanic eruption years. The climatology is calculated by taking the prior $5 \mathrm{yr}$, skipping the volcanic eruption year and $2 \mathrm{yr}$ after, and then using the next $5 \mathrm{yr}$. The dashed lines represent confidence intervals of $95 \%$ and $99 \%$ derived from 1000 Monte Carlo simulations.

the volcanic eruption year and the two years after and returns to normal conditions thereafter (Fig. 5b). This temporal development of the precipitation response to large volcanic eruptions is similar to that revealed by modeled and observed tropical precipitation (Robock and Liu 1994) and global precipitation (Gillett et al. 2004).

The global pattern of SAT and precipitation anomalies in the first summer after the 21 large volcanic eruptions are shown in Fig. 6. Cooling anomalies in the first summer after large volcanic eruptions are seen on a nearly global scale (Fig. 6a). The cooling anomalies are significantly enhanced over Eurasia and North America, with a maximum of about $-0.8^{\circ} \mathrm{C}$. The global-mean SAT anomalies are $-0.58^{\circ} \mathrm{C}$ after the significance test based on the 5\% significance level derived from 1000 Monte Carlo simulations. The cooling in the extratropical $\mathrm{NH}\left(-0.46^{\circ} \mathrm{C}\right)$ is stronger than in the extratropical $\mathrm{SH}$ 
(a) SAT

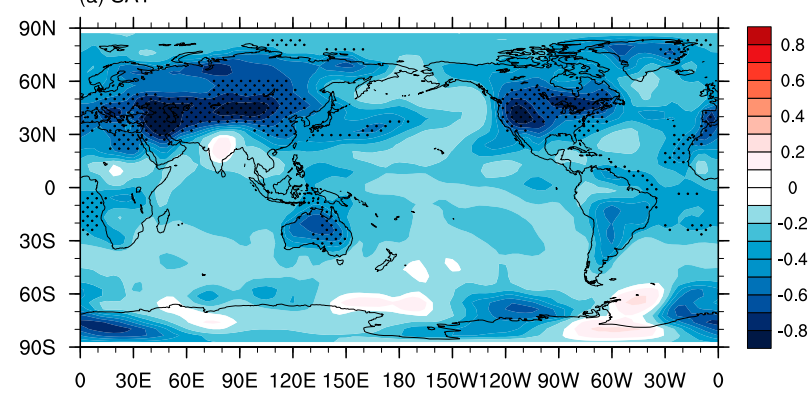

(b) PREC_UV850

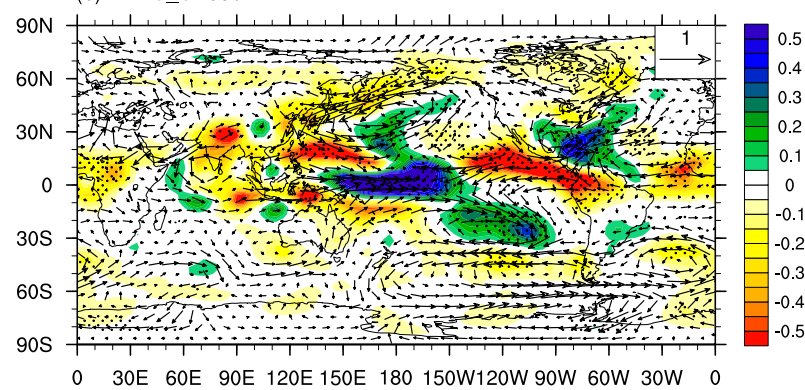

- 30E 60E 90E 120E 150E 180 150W120W 90W 60W 30W

FIG. 6. Composite means of global (a) SAT $\left({ }^{\circ} \mathrm{C}\right)$ and (b) precipitation (color shading; $\mathrm{mm} \mathrm{day}^{-1}$ ) and $850-\mathrm{hPa}$ winds (vectors; $\mathrm{m} \mathrm{s}^{-1}$ ) in the first summer after the 21 large volcanic eruptions. The climatology is calculated by taking the prior $5 \mathrm{yr}$, skipping the volcanic eruption year and $2 \mathrm{yr}$ after, and then using the next $5 \mathrm{yr}$. The regions shaded by black dots denote colored areas that are significant at the 5\% level derived from 1000 Monte Carlo simulations.

$\left(-0.19^{\circ} \mathrm{C}\right)$ and is stronger over the continents $\left(-0.43^{\circ} \mathrm{C}\right)$ than over the ocean $\left(-0.24^{\circ} \mathrm{C}\right)$. The polar-amplification phenomenon of the SAT anomalies after large volcanic eruptions is most evident in the NH. This response is consistent with previous findings that a global cooling is seen after the volcanic eruptions and that the cooling is most evident over the middle-to-high latitude continent regions ( $\mathrm{Li}$ et al. 1996).

The precipitation anomaly patterns in the first summer after large volcanic eruptions are shown in Fig. 6b. The simulation exhibits the strongest precipitation response in the tropics and subtropics. Significant negative precipitation anomalies are seen in the tropics, including the tropical Indian Ocean, the tropical western Pacific, the tropical eastern Pacific, and the tropical Atlantic Ocean. There are significant positive precipitation anomalies in the tropical central Pacific. The simulated tropical SST patterns in the first summer after large volcanic eruptions could be a reason for the tropical precipitation patterns. Negative SST anomalies are seen in the western tropical Pacific (not shown), which will lead to negative precipitation anomalies adjacent to the west coast of the Philippines. The heating associated with deficient precipitation further favors the upward motion in the central tropical Pacific and leads to positive precipitation
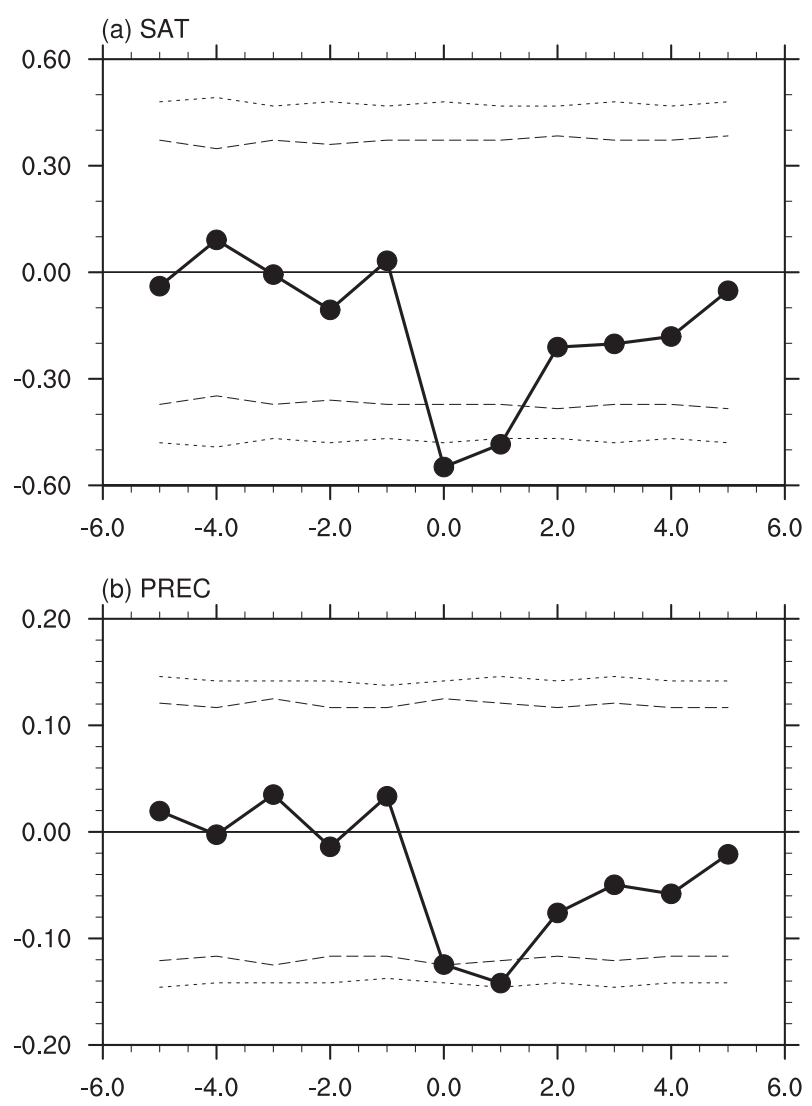

FIG. 7. The SEA results of summer (a) SAT $\left({ }^{\circ} \mathrm{C}\right)$ and (b) precipitation $\left(\mathrm{mm} \mathrm{day}^{-1}\right)$ over eastern China for the 21 cases of large volcanic eruptions in the 5 prevolcanic eruption years, the volcanic eruption year, and the 5 postvolcanic eruption years. The climatology is calculated by taking the prior $5 \mathrm{yr}$, skipping the volcanic eruption year and $2 \mathrm{yr}$ after, and then using the next $5 \mathrm{yr}$. The dashed lines represent confidence intervals of $95 \%$ and $99 \%$ derived from 1000 Monte Carlo simulations.

anomalies there. In addition to the tropical precipitation patterns, negative precipitation anomalies are also seen in the middle-to-high latitude continent regions. The precipitation responses to large volcanic eruptions are consistent with previous findings that negative precipitation anomalies are seen in many regions after large eruptions, such as in the tropics (Robock and Liu 1994) and the central and eastern parts of North America (Portman and Gutzler 1996).

The temporal patterns of summer SAT and precipitation anomalies over eastern China for the 21 cases of large volcanic eruptions in the five prevolcanic eruption years, volcanic eruption year, and five postvolcanic eruption years are further shown in Fig. 7. The largest reduction of the SAT anomalies over eastern China appears in the volcanic eruption year and the year after (Fig. 7a). A statistically significant reduction in summer precipitation is also indicated beginning in the 
(a) SAT

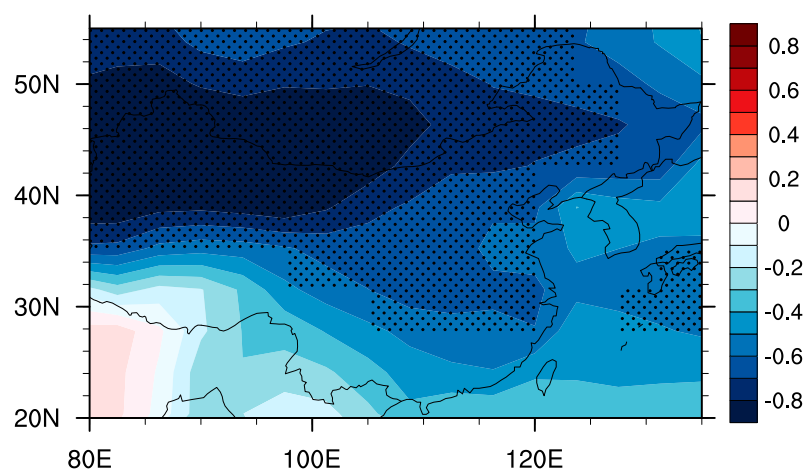

(b) PREC_UV850

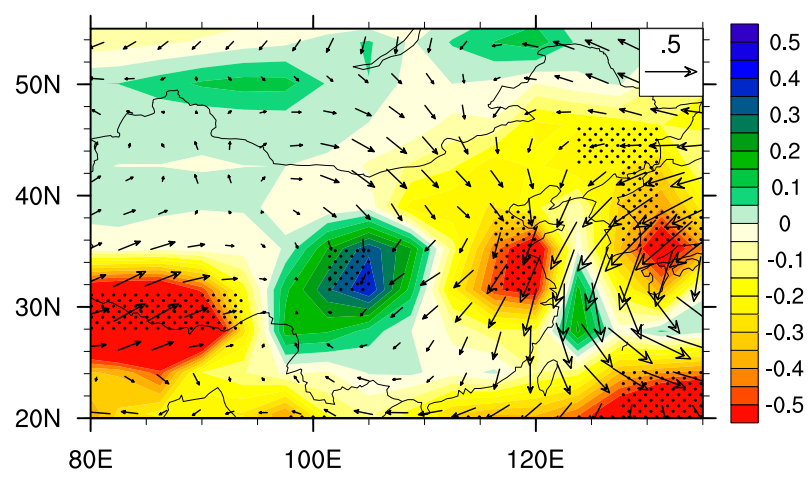

FIG. 8. Composite means of (a) SAT $\left({ }^{\circ} \mathrm{C}\right)$ and (b) precipitation (color shading; $\mathrm{mm} \mathrm{day}^{-1}$ ) and $850-\mathrm{hPa}$ winds (vectors; $\mathrm{m} \mathrm{s}^{-1}$ ) in the first summer after the 21 large volcanic eruptions. The climatology is calculated by taking the prior $5 \mathrm{yr}$, skipping the volcanic eruption year and $2 \mathrm{yr}$ after, and then using the next $5 \mathrm{yr}$. The regions shaded by black dots denote colored areas that are significant at the $5 \%$ level derived from 1000 Monte Carlo simulations.

same year as the eruption and persisting for 1-2 more years (Fig. 7b). This temporal pattern in the response of summer precipitation to large volcanic eruptions is similar to that revealed by Peng et al. (2010), who also suggested a reduction of summer precipitation after large volcanic eruptions.

The SAT and precipitation anomaly patterns over East Asia in the first summer after the 21 large volcanic eruptions are shown in Fig. 8. Significant cooling anomalies are seen over East Asia after large volcanic eruptions (Fig. 8a). The cooling over the middle-to-high latitudes of East Asia is stronger than over the tropical ocean, which suggests a reduced land-sea thermal contrast. Anomalies of $850-\mathrm{hPa}$ winds in the first summer after large volcanic eruptions indicate that East Asia is dominated by northerly wind anomalies, which correspond to a weaker EASM (Fig. 8b). The corresponding summer rainfall anomalies exhibit a coherent reduction over all of eastern China, with a significant reduction center in central eastern China (Fig. 8b). Our results are (a) Millennial mean

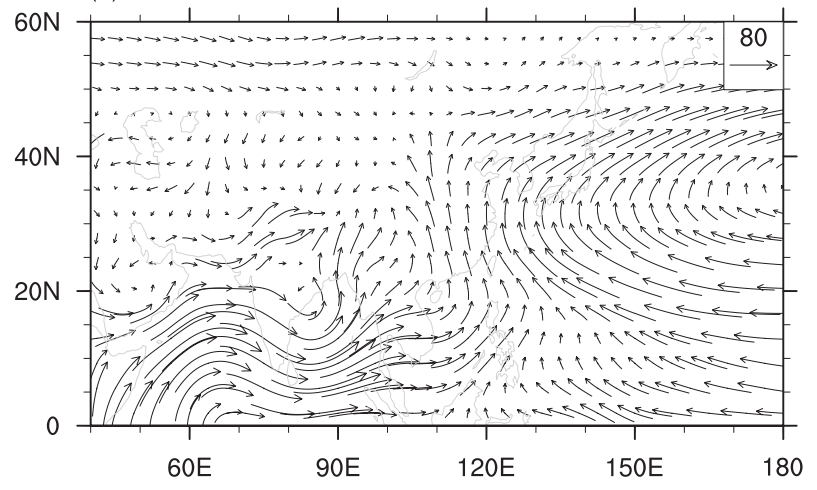

(b) Composite means

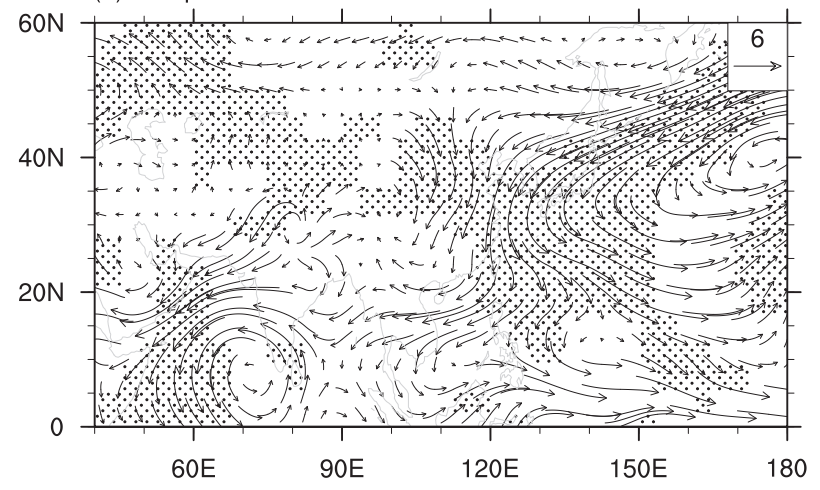

FIG. 9. The $850-\mathrm{hPa}$ water vapor transport $\left(\mathrm{kg} \mathrm{m}^{-1} \mathrm{~s}^{-1}\right)$ for (a) the millennial mean and (b) the composite means in the first summer after the 21 large volcanic eruptions. The climatology is calculated by taking the prior $5 \mathrm{yr}$, skipping the volcanic eruption year and $2 \mathrm{yr}$ after, and then using the next $5 \mathrm{yr}$. The regions shaded by black dots denote areas with meridional components that are significant at the 5\% level derived from 1000 Monte Carlo simulations.

consistent with proxy data analysis that low-latitude volcanic eruptions might lead to coherent droughts over eastern China (Shen et al. 2008). Thus, it seems reasonable to conclude that volcanic eruptions play a role in the drought in eastern China.

\section{c. Attribution of monsoon circulation changes}

The water vapor transport is crucial to monsoon rainfall (Zhou and $\mathrm{Yu}$ 2005). There are three main branches of climatological $850-\mathrm{hPa}$ water vapor transport to East Asia (Fig. 9a): a strong transport by the southwesterlies from the Indian monsoon, a moderate transport by the Southeast Asian monsoon from the western Pacific, and a weak transport of cross-equator flow straddling $105^{\circ}-150^{\circ} \mathrm{E}$. Anomalies of summer $850-\mathrm{hPa}$ water vapor transport after the volcanic eruptions are shown in Fig. 9b. The anomalous water vapor transport by both the southwesterlies from the Indian monsoon and the southeasterlies from the western 
(a) $\mathrm{T} 200-500$

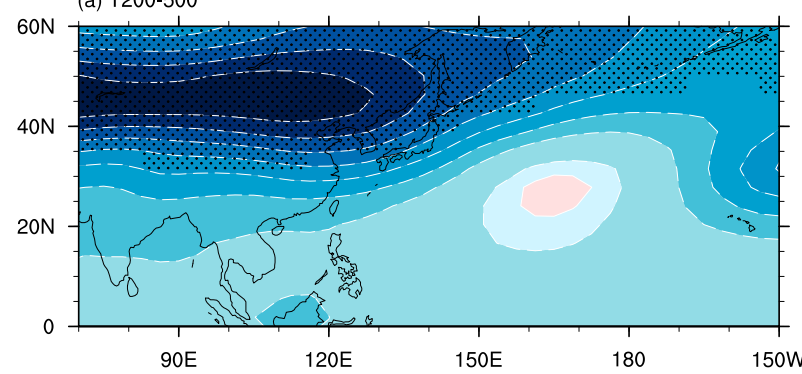

(b) MTG

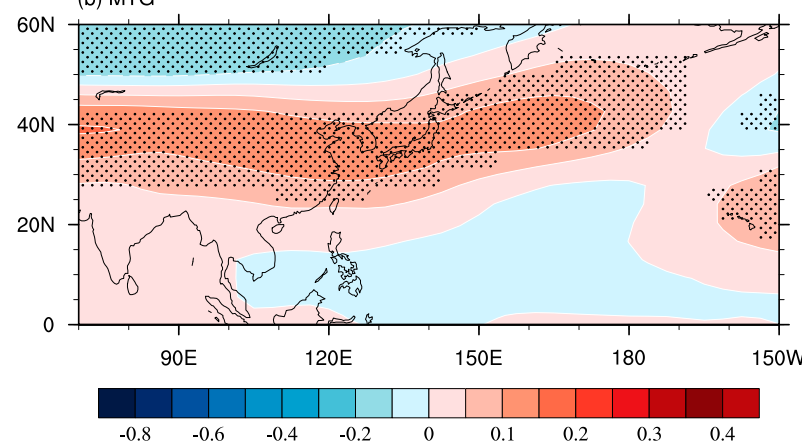

FIG. 10. Composite means of (a) the middle-to-upper tropospheric mean $(500-200 \mathrm{hPa})$ temperature anomalies $\left({ }^{\circ} \mathrm{C}\right)$ and $(\mathrm{b})$ the MTG in the first summer after the 21 large volcanic eruptions. The climatology is calculated by taking the prior $5 \mathrm{yr}$, skipping the volcanic eruption year and $2 \mathrm{yr}$ after, and then using the next $5 \mathrm{yr}$. The regions shaded by black dots denote areas that are significant at the 5\% level derived from 1000 Monte Carlo simulations.

Pacific are significantly negative; added to the anomalous northerly winds over East Asia, this contributes to significantly reducing the northward transport of tropical water vapor to northern China. This leads to deficient rainfall over eastern China after large volcanic eruptions. The study by Peng et al. (2010) suggested that the reduction of summer precipitation over eastern China can be attributed to the decrease of the latent heat flux and thus the evaporation over tropical oceans, which was the main moisture source of summer precipitation over eastern China. The significance of our results indicates that the drought is mainly due to the weakening of the summer monsoon circulations.

The land-sea thermal contrast change could be used to explain the monsoon response to large volcanic eruptions. The tropospheric mean temperature is a reasonable indicator of thermal contrast change (Zhou and Zou 2010). The tropospheric mean (200-500-hPa average) temperature anomalies after large volcanic eruptions are shown in Fig. 10. Significant cooling anomalies with amplitudes of up to $-0.8^{\circ} \mathrm{C}$ are seen over East Asia (Fig. 10a), which are stronger than the cooling anomalies in the tropical western Pacific and extratropical North Pacific. The meridional temperature gradient (MTG) further indicates that the magnitude of the (a) Zonal

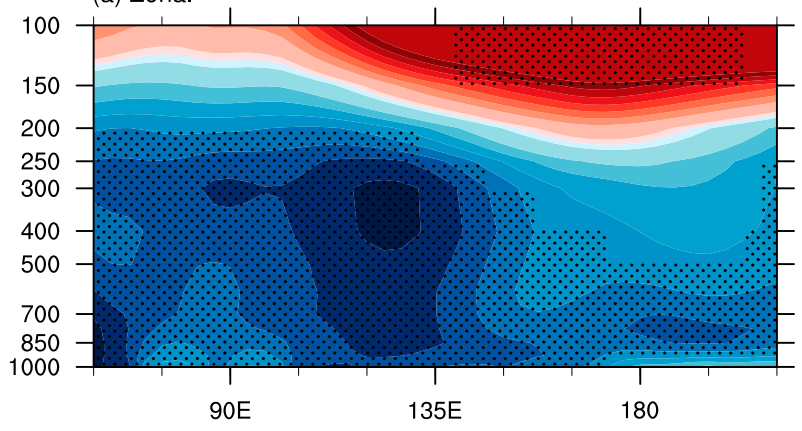

(b) Meridional

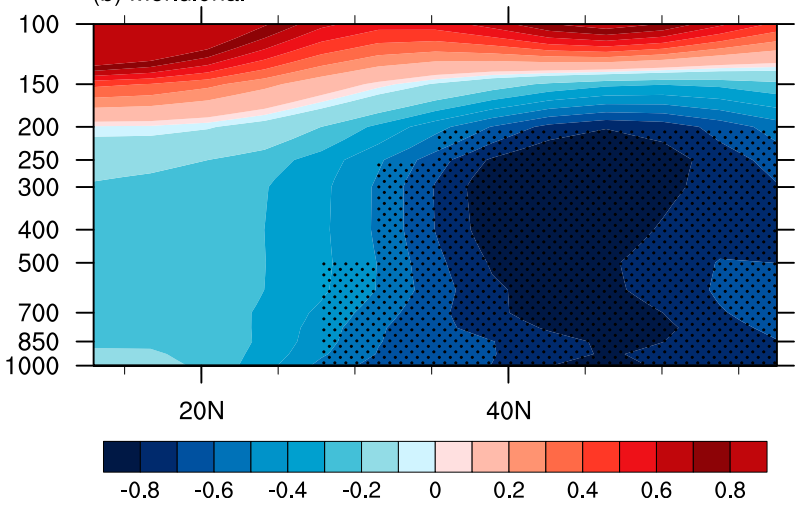

FIG. 11. (a) Longitude-height cross section of temperature averaged over $30^{\circ}-45^{\circ} \mathrm{N}\left({ }^{\circ} \mathrm{C}\right)$ and (b) latitude-height cross section of temperature averaged over $105^{\circ}-122^{\circ} \mathrm{E}\left({ }^{\circ} \mathrm{C}\right)$ in the first summer after the 21 large volcanic eruptions. The climatology is calculated by taking the prior $5 \mathrm{yr}$, skipping the volcanic eruption year and $2 \mathrm{yr}$ after, and then using the next $5 \mathrm{yr}$. The regions shaded by black dots denote areas that are significant at the 5\% level derived from 1000 Monte Carlo simulations.

cooling anomalies in the middle-to-high latitudes is significantly stronger than in the lower latitudes (Fig. $10 \mathrm{~b})$. This anomaly pattern suggests a reduced land-sea thermal contrast and favors a weaker EASM circulation after large volcanic eruptions.

The corresponding structures at vertical cross sections are shown in Fig. 11 in order to give a clear picture of both the zonal and the meridional land-sea thermal contrast change. The zonal land-sea thermal contrast along $30^{\circ}-45^{\circ} \mathrm{N}$ depicted by the height-longitude cross section exhibits cooling anomalies in the middle-to-upper troposphere after large volcanic eruptions (Fig. 11a). Significantly cooler anomalies with a maximum of $-0.8^{\circ} \mathrm{C}$ are seen over Eurasia extending from $90^{\circ}$ to $135^{\circ} \mathrm{E}$. The magnitude of the cooling anomalies over the ocean is much weaker than over the land. This anomaly pattern indicates that the zonal land-sea thermal contrast decreases significantly after large volcanic eruptions.

The height-latitude cross section measuring the meridional land-sea thermal contrast also exhibits cooling anomalies in the middle-to-upper troposphere after large 
volcanic eruptions (Fig. 11b). The "colder land" is significantly evident with a maximum cooling of $-0.8^{\circ} \mathrm{C}$ below $200 \mathrm{hPa}$ extending from $40^{\circ}$ to $60^{\circ} \mathrm{N}$. The magnitude of the negative temperature anomalies over the ocean is much weaker than over the land; thus, the meridional land-sea thermal contrast is evident and favors a weaker summer monsoon.

The change in the radiative fluxes at the top of the atmosphere (TOA) characterizes the change in the energy input into the whole climate system. Figure 12 shows the spatial patterns in the radiative fluxes after large volcanic eruptions. There are significant reductions in both the absorbed shortwave radiation and the emitted longwave radiation. The reduction in the emitted longwave radiation after large volcanic eruptions could be due to the changed total cloud coverage (not shown). The reduction of the shortwave radiation reached its largest value of more than $-8 \mathrm{~W} \mathrm{~m}^{-2}$ in the first summer after large volcanic eruptions (Fig. 12a), while the longwave radiation reduction was much weaker than in the shortwave radiation, with about a $-4 \mathrm{~W} \mathrm{~m}^{-2}$ reduction in the model (Fig. 12b). The reductions in the shortwave radiation are nearly twice as large as the reduction in emitted longwave radiation, a net loss of radiative energy that cools the surface and lower troposphere. The results indicate that the shortwave forcings from volcanic eruptions exert a large influence on the temperature and precipitation changes.

\section{Summary and discussion}

\section{a. Summary}

Responses of summer temperatures and precipitation to large volcanic eruptions are analyzed by using the millennial simulations with the MPI Earth System Model. The main results are summarized below:

1) A statistically significant reduction in summer temperature and precipitation is indicated beginning in the volcanic eruption year and persisting for 1-2 more years. Cooling anomalies in the first summer after large volcanic eruptions are seen on a nearly global scale. The cooling in the $\mathrm{NH}$ is stronger than in the $\mathrm{SH}$ and is stronger over the continents than over the ocean.

2) Significant surface cooling anomalies are seen over East Asia after large volcanic eruptions, especially in the middle-to-high latitudes of East Asia. East Asia is dominated by northerly wind anomalies, which correspond to a weaker EASM. The summer rainfall exhibits a coherent reduction over eastern China, with a significant reduction center located in central eastern China. (a) TOA shortwave radiation flux

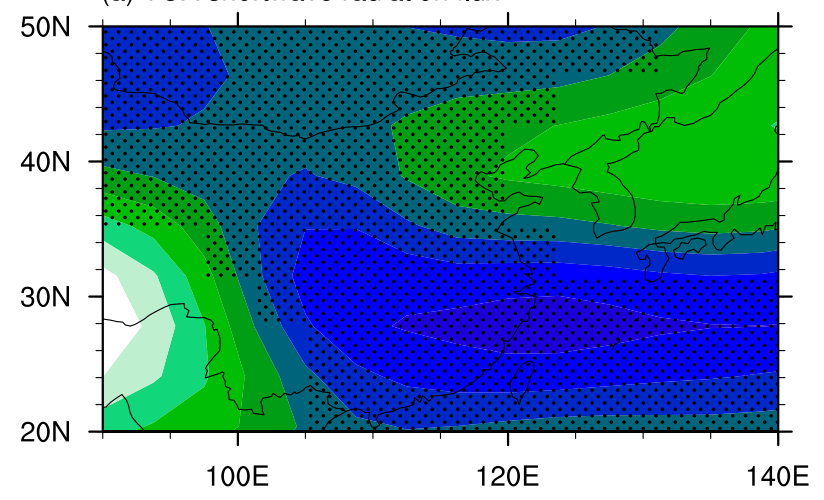

(b) TOA longwave radiation flux

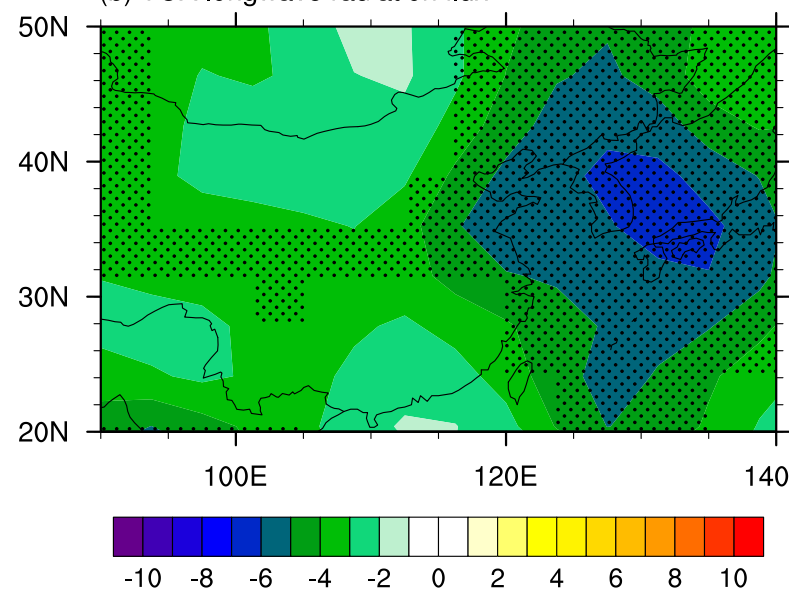

FIG. 12. The spatial patterns of the radiative fluxes at the top of the atmosphere in the first summer after the 21 large volcanic eruptions $\left(\mathrm{W} \mathrm{m}^{-2}\right)$ : (a) the absorbed shortwave radiation flux and (b) the emitted longwave radiation flux. The climatology is calculated by taking the prior $5 \mathrm{yr}$, skipping the volcanic eruption year and $2 \mathrm{yr}$ after, and then using the next $5 \mathrm{yr}$. The regions shaded by black dots denote areas that are significant at the $5 \%$ level derived from 1000 Monte Carlo simulations.

3) The water vapor transport is crucial to monsoon rainfall. The anomalous water vapor transport by both the southwesterlies from the Indian monsoon and the southeasterlies from the western Pacific are significantly negative; added to the anomalous northerly winds over East Asia, this contributes to significantly reducing the northward transport of tropical water vapor to northern China. The results indicate that the weakening of the monsoon circulation leads to deficient rainfall over eastern China after large volcanic eruptions.

4) The tropospheric mean temperature is used as an indicator for land-sea thermal contrast change. Significant cooling anomalies with a maximum of $-0.8^{\circ} \mathrm{C}$ are seen over East Asia, which are stronger than the cooling anomalies in the tropical western Pacific and extratropical North Pacific. The MTG analysis further indicates that the magnitude of the 
cooling anomalies in the middle-to-high latitudes is significantly stronger than in the lower latitudes. This anomaly pattern suggests a reduced land-sea thermal contrast and favors a weaker EASM circulation after large volcanic eruptions.

5) The corresponding structures at vertical cross sections are further analyzed to describe both the zonal and the meridional land-sea thermal contrast change. Both structures exhibit significantly colder land after large volcanic eruptions, while the magnitude of cooling anomalies over the ocean is much weaker. This suggests a reduced zonal and meridional landsea thermal contrast and favors a weaker summer monsoon circulation.

6) The analysis of the radiative fluxes at TOA suggests that the reductions in the shortwave radiation after large volcanic eruptions are nearly twice as large as the reduction in emitted longwave radiation, a net loss of radiative energy that cools the surface and lower troposphere.

\section{b. Discussion}

As in previous studies, we find that volcanic eruptions do not result in globally or even regionally uniform summer cooling (Schneider et al. 2009; Anchukaitis et al. 2012), and the state of the ENSO system may, in part, determine the sign and magnitude of the resulting temperature anomalies (Zhang et al. 2013). In this study, the model fails to reproduce the observed El Niño events after the volcanic eruptions, which lead to the large discrepancy between the simulated and the observed temperature and precipitation patterns. The occurrence of El Niño events after large volcanic eruptions is supported by simulations employing the simplified Zebiak-Cane model of the tropical Pacific coupled ocean-atmosphere system (Mann et al. 2005). However, most GCM simulations fail to reproduce the occurrence of El Niño events after large volcanic eruptions, because the GCMs may not capture all of the important oceanatmosphere dynamics (Anchukaitis et al. 2010). Thus, simulations where the model is adjusted to the observed ENSO state are needed in future study.

Explosive volcanism is an important radiative forcing factor of climate over Asia. Anchukaitis et al. (2010) used well-dated proxy reconstructions of Asian droughts to detect the influence of volcanic radiative forcing on the hydroclimate of the region. The analysis reveals significantly wetter conditions over mainland Southeast Asia in the year of an eruption, with drier conditions in central Asia. However, several GCMs suggest nearly opposite-signed event year anomalies in these regions compared to the paleoclimate data. This disagreement suggests that the GCMs do not correctly capture the coupled ocean-atmosphere processes involved in the response of the Asian climate to radiative forcing. Zhang et al. (2013) assessed the cooperative effects and impacts of volcanic eruptions and ENSO events in MPIESM ensemble climate simulations and compared it with reconstructions in East Asia. The results also indicated that the coldness and drought over eastern China depends crucially on the ENSO state of the coupled model. However, the simulated occurrence of El Niño events is not significantly increased after volcanic eruptions. The result appears to be in disagreement with reconstructions (Adams et al. 2003). The disagreements also provide important clues toward further refinement of the climate models in future work.

It should also be noted that there are strong warming anomalies in the higher levels of the troposphere at the vertical cross sections of the tropospheric temperature (Fig. 11). What is the reason responsible for the warming here? As we all know, the volcanic eruptions inject a large amount of particles and gases into the stratosphere, and these stratospheric aerosols reflect the radiation from the Sun, thus cooling the troposphere. Furthermore, these stratospheric aerosols can also absorb both solar nearinfrared and outgoing longwave radiation, which in turn will lead to a warming of the stratosphere (Robock 2000). In the model simulation, however, the climatological mean tropopause locates in $200-150 \mathrm{hPa}$ over East Asia (not shown). The higher levels of the troposphere in Fig. 11 are, in fact, the stratosphere in the model. The stratospheric aerosols can thus lead to strong warming anomalies after large volcanic eruptions.

Acknowledgments. This work was jointly supported by the National Natural Science Foundation of China (Grant 41305069), China R\&D Special Fund for Public Welfare Industry (meteorology) (GYHY201406020), the Open Project Program of the Key Laboratory of Meteorological Disaster of the Ministry of Education, Nanjing University of Information Science and Technology, and the National Program on Key Basic Research Project of China (Grant 2010CB951904). Johann H. Jungclaus was partly supported by the Deutsche Forschungsgemeinschaft (DFG) under Grant JU311/7-1.

\section{REFERENCES}

Adams, J. B., M. E. Mann, and C. M. Ammann, 2003: Proxy evidence for an El Niño-like response to volcanic forcing. Nature, 426, 274-278, doi:10.1038/nature02101.

Allen, M. R., and W. J. Ingram, 2002: Constraints on future changes in climate and the hydrologic cycle. Nature, 419, 224-232, doi:10.1038/nature01092.

Ammann, C. M., F. Joos, D. Schimel, B. L. Otto-Bliesner, and R. A. Tomas, 2007: Solar influence on climate during the past 
millennium: Results from transient simulations with the NCAR Climate System Model. Proc. Natl. Acad. Sci. USA, 104, 3713-3718, doi:10.1073/pnas.0605064103.

Anchukaitis, K. J., B. M. Buckley, E. R. Cook, B. I. Cook, R. D. D'Arrigo, and C. M. Ammann, 2010: Influence of volcanic eruptions on the climate of the Asian monsoon region. Geophys. Res. Lett., 37, L22703, doi:10.1029/2010GL044843.

- - and Coauthors, 2012: Tree rings and volcanic cooling. Nat. Geosci., 5, 836-837, doi:10.1038/ngeo1645.

Bradbury, J. A., 2006: Reconstructing the East Asian monsoon response to major volcanic eruptions: A test of model skill with instrumental and paleoclimate data. Ph.D. dissertation, University of Massachusetts, $254 \mathrm{pp}$.

Broccoli, A. J., K. W. Dixon, T. L. Delworth, T. R. Knutson, R. J. Stouffer, and F. Zeng, 2003: Twentieth-century temperature and precipitation trends in ensemble climate simulations including natural and anthropogenic forcing. J. Geophys. Res., 108, 4798, doi:10.1029/2003JD003812.

Chen, M., P. Xie, J. Janowiak, and P. A. Arkin, 2002: Global land precipitation: A 50-yr monthly analysis based on gauge observations. J. Hydrometeor., 3, 249-266, doi:10.1175/ 1525-7541(2002)003<0249:GLPAYM>2.0.CO;2.

Crowley, T. J., T. A. Criste, and N. R. Smith, 1993: Reassessment of Crete (Greenland) ice core acidity/volcanism link to climate change. Geophys. Res. Lett., 20, 209-212, doi:10.1029/ 93GL00207.

-, G. Zielinski, B. Vinther, R. Udisti, K. Kreutz, J. Cole-Dai, and E. Castellano, 2008: Volcanism and the little ice age. PAGES Newsletter, Vol. 16, PAGES International Project Office, Bern, Switzerland, 22-23.

Ding, Y. H., 1992: Summer monsoon rainfalls in China. J. Meteor. Soc. Japan, 70, 373-396.

Dutton, E. G., and J. R. Christy, 1992: Solar radiative forcing at selected locations and evidence for global lower tropospheric cooling following the eruptions of El Chichón and Pinatubo. Geophys. Res. Lett., 19, 2313-2316, doi:10.1029/92GL02495.

Fan, F., M. E. Mann, and C. M. Ammann, 2009: Understanding changes in the Asian summer monsoon over the past millennium: Insights from a long-term coupled model simulation. J. Climate, 22, 1736-1748, doi:10.1175/2008JCLI2336.1.

Fasullo, J., 2004: A stratified diagnosis of the Indian monsoonEurasian snow cover relationship. J. Climate, 17, 1110-1122, doi:10.1175/1520-0442(2004)017<1110:ASDOTI>2.0.CO;2.

Gillett, N. P., A. J. Weaver, F. W. Zwiers, and M. F. Wehner, 2004: Detection of volcanic influence on global precipitation. Geophys. Res. Lett., 31, L12217, doi:10.1029/2004GL020044.

Gong, D., and S. Wang, 2000: Severe summer rainfall in China associated with enhanced global warming. Climate Res., 16, 51-59, doi:10.3354/cr016051.

Graf, H.-F., 1992: Arctic radiation deficit and climate variability. Climate Dyn., 7, 19-28, doi:10.1007/BF00204818.

Hahn, D., and J. Shukla, 1976: An apparent relationship between Eurasian snow cover and Indian monsoon rainfall. J. Atmos. Sci., 33, 2461-2462, doi:10.1175/1520-0469(1976)033<2461: AARBES $>2.0 . \mathrm{CO} ; 2$.

Hansen, J., A. Lacis, R. Ruedy, and M. Sato, 1992: Potential climate impact of Mount Pinatubo eruption. Geophys. Res. Lett., 19, 215-218, doi:10.1029/91GL02788.

— R. Ruedy, M. Sato, and K. Lo, 2010: Global surface temperature change. Rev. Geophys., 48, RG4004, doi:10.1029/ 2010RG000345.

Haurwitz, M. W., and G. W. Brier, 1981: A critique of the superposed epoch analysis method: Its application to solar-weather relations. Mon. Wea. Rev., 109, 2074-2079, doi:10.1175/ 1520-0493(1981)109<2074:ACOTSE > 2.0.CO;2.

Hibler, W. D., 1979: A dynamic thermodynamic sea ice model. J. Phys. Oceanogr., 9, 815-846, doi:10.1175/1520-0485(1979)009<0815: $\mathrm{ADTSIM}>2.0 . \mathrm{CO} ; 2$.

Jungclaus, J. H., and Coauthors, 2010: Climate and carbon-cycle variability over the last millennium. Climate Past, 6, 723-737, doi:10.5194/cp-6-723-2010.

Kirchner, I., G. L. Stenchikov, H.-F. Graf, A. Robock, and J. C. Antuña, 1999: Climate model simulation of winter warming and summer cooling following the 1991 Mount Pinatubo volcanic eruption. J. Geophys. Res., 104, 19039-19055, doi:10.1029/ 1999JD900213.

Lambert, F. H., P. A. Stott, M. R. Allen, and M. A. Palmer, 2004: Detection and attribution of changes in 20th century land precipitation. Geophys. Res. Lett., 31, L10203, doi:10.1029/ 2004GL019545.

Landrum, L., B. L. Otto-Bliesner, E. R. Wahl, A. Conley, P. J. Lawrence, N. Rosenbloom, and H. Y. Teng, 2013: Last millennium climate and its variability in CCSM4. J. Climate, 26, 1085-1111, doi:10.1175/JCLI-D-11-00326.1.

Li, X. D., S. W. Wang, and R. X. Liu, 1996: The advances in volcano-climatology (in Chinese). Seismol. Geomagn. Obs. Res., 17, 74-80.

Liu, X. D., and M. Yanai, 2002: Influence of Eurasian spring snow cover on Asian summer rainfall. Int. J. Climatol., 22, 10751089, doi:10.1002/joc.784.

MacFarling Meure, C., D. Etheridge, C. Trudinger, P. Steele, R. Langenfelds, T. van Ommen, A. Smith, and J. Elkins, 2006: Law Dome $\mathrm{CO}_{2}, \mathrm{CH}_{4}$ and $\mathrm{N}_{2} \mathrm{O}$ ice core records extended to 2000 years BP. Geophys. Res. Lett., 33, L14810, doi:10.1029/ 2006 GL026152.

Man, W., T. Zhou, and J. Jungclaus, 2012: Simulation of the East Asian summer monsoon during the last millennium with the MPI Earth System Model. J. Climate, 25, 7852-7866, doi:10.1175/JCLI-D-11-00462.1.

Mann, M. E., M. A. Cane, S. E. Zebiak, and A. Clement, 2005: Volcanic and solar forcing of the tropical Pacific over the past 1000 years. J. Climate, 18, 447-456, doi:10.1175/JCLI-3276.1.

Marsland, S. J., H. Haak, J. H. Jungclaus, M. Latif, and F. Röske, 2003: The Max-Planck-Institute global ocean/sea ice model with orthogonal curvilinear coordinates. Ocean Modell., 5, 91 127, doi:10.1016/S1463-5003(02)00015-X.

Minnis, P., E. F. Harrison, L. L. Stowe, G. G. Gibson, F. M. Denn, D. R. Doelling, and W. L. Smith Jr., 1993: Radiative climate forcing by the Mount Pinatubo eruption. Science, 259, 14111415, doi:10.1126/science.259.5100.1411.

Mitchell, J. F. B., and Coauthors, 2001: Detection of climate change and attribution of causes. Climate Change 2001: The Scientific Basis, J. T. Houghton et al., Eds., Cambridge University Press, 695-738.

Newhall, C. G., and S. Self, 1982: The volcanic explosivity index (VEI) an estimate of explosive magnitude for historical volcanism. J. Geophys. Res., 87, 1231-1238, doi:10.1029/JC087iC02p01231.

Oman, L., A. Robock, G. L. Stenchikov, G. A. Schmidt, and R. Ruedy, 2005: Climatic response to high-latitude volcanic eruptions. J. Geophys. Res., 110, D13103, doi:10.1029/2004JD005487.

-,$-\ldots$, and T. Thordarson, 2006: High-latitude eruptions cast shadow over the African monsoon and the flow of the Nile. Geophys. Res. Lett., 33, L18711, doi:10.1029/2006GL027665.

Peng, Y. B., C. Shen, W.-C. Wang, and Y. Xu, 2010: Response of summer precipitation over eastern China to large volcanic eruptions. J. Climate, 23, 818-824, doi:10.1175/2009JCLI2950.1. 
Phipps, S. J., L. D. Rotstayn, H. B. Gordon, J. L. Roberts, A. C. Hirst, and W. F. Budd, 2012: The CSIRO Mk3L climate system model version 1.0-Part 2: Response to external forcings. Geosci. Model Dev., 5, 649-682, doi:10.5194/gmd-5-649-2012.

Pongratz, J., C. H. Reick, T. Raddatz, and M. Claussen, 2008: A reconstruction of global agricultural areas and land cover for the last millennium. Global Biogeochem. Cycles, 22, GB3018, doi:10.1029/2007GB003153.

Portman, D. A., and D. S. Gutzler, 1996: Explosive volcanic eruptions, the El Niño-Southern Oscillation, and U.S. climate variability. J. Climate, 9, 17-33, doi:10.1175/1520-0442(1996)009<0017: EVETEN $>2.0 . \mathrm{CO} ; 2$.

Raddatz, T. J., and Coauthors, 2007: Will the tropical land biosphere dominate the climate-carbon cycle feedback during the twenty-first century? Climate Dyn., 29, 565-574, doi:10.1007/ s00382-007-0247-8.

Robock, A., 2000: Volcanic eruptions and climate. Rev. Geophys., 38, 191-219, doi:10.1029/1998RG000054.

_ 2002: Pinatubo eruption: The climatic aftermath. Science, 295, 1242-1244, doi:10.1126/science.1069903.

__ and J. Mao, 1992: Winter warming from large volcanic eruptions. Geophys. Res. Lett., 19, 2405-2408, doi:10.1029/ 92GL02627.

_ and Y. Liu, 1994: The volcanic signal in Goddard Institute for Space Studies three-dimensional model simulations. J. Climate, 7, 44-55, doi:10.1175/1520-0442(1994)007<0044: TVSIGI $>2.0 . \mathrm{CO} ; 2$.

Roeckner, E., and Coauthors, 2003: The atmosphere general circulation model ECHAM5. Part I: Model description. Max Planck Institute for Meteorology Tech. Rep. 349, 127 pp. [Available online at http:/www.mpimet.mpg.de/fileadmin/ publikationen/Reports/max_scirep_349.pdf.]

Schmidt, G. A., and Coauthors, 2014: Configuration and assessment of the GISS ModelE2 contributions to the CMIP5 archive. J. Adv. Model. Earth Syst., 6, 141-184, doi:10.1002/ 2013MS000265.

Schneider, D. P., C. M. Ammann, B. L. Otto-Bliesner, and D. S. Kaufman, 2009: Climate response to large, high-latitude and low-latitude volcanic eruptions in the Community Climate System Model. J. Geophys. Res., 114, D15101, doi:10.1029/ 2008JD011222.

Shen, C. M., W. C. Wang, Z. X. Hao, and W. Gong, 2007: Exceptional drought events over eastern China during the last five centuries. Climatic Change, 85, 453-471, doi:10.1007/ s10584-007-9283-y.

$-\ldots, \ldots, \ldots$, and -2008 : Characteristics of anomalous precipitation events over eastern China during the past five centuries. Climate Dyn., 31, 463-476, doi:10.1007/ s00382-007-0323-0.

Stowe, L., R. Carey, and P. Pellegrino, 1992: Monitoring the Mt. Pinatubo aerosol layer with NOAA/11 AVHRR data. Geophys. Res. Lett., 19, 159-162, doi:10.1029/91GL02958.

Tao, S., W. Zhu, and W. Zhao, 1988: Interannual variability of Meiyu rainfall (in Chinese). Chinese J. Atmos. Sci., 12, 13-21.
Timmreck, C., S. J. Lorenz, T. J. Crowley, S. Kinne, T. J. Raddatz, M. A. Thomas, and J. H. Jungclaus, 2009: Limited temperature response to the very large AD 1258 volcanic eruption. Geophys. Res. Lett., 36, L21708, doi:10.1029/2009GL040083.

_ , H.-F. Graf, S. J. Lorenz, U. Niemeier, D. Zanchettin, D. Matei, J. H. Jungclaus, and T. J. Crowley, 2010: Aerosol size confines climate response to volcanic super-eruptions. Geophys. Res. Lett., 37, L24705, doi:10.1029/2010GL045464.

Trenberth, K. E., and A. G. Dai, 2007: Effects of Mount Pinatubo volcanic eruption on the hydrological cycle as an analog of geoengineering. Geophys. Res. Lett., 34, L15702, doi:10.1029/ 2007GL030524.

Trepte, C. R., R. E. Veiga, and M. P. McCormick, 1993: The poleward dispersal of Mount Pinatubo volcanic aerosol. J. Geophys. Res., 98, 18563-18573, doi:10.1029/93JD01362.

Valcke, S., A. Caubel, D. Declat, and L. Terray, 2003: OASIS3 Ocean Atmosphere Sea Ice Soil user's guide. CERFACS Tech. Rep. TR/CGMC/03/69, 85 pp. [Available online at http:// www.cerfacs.fr/globc/publication/technicalreport/2003/oasis3_ UserGuide.pdf.]

Vieira, L. E. A., S. K. Solanki, N. A. Krivova, and I. Usoskin, 2011: Evolution of the solar irradiance during the Holocene. Astron. Astrophys., 531, A6, doi:10.1051/0004-6361/201015843.

Wetzel, P., E. Maier-Reimer, M. Botzet, J. Jungclaus, N. Keenlyside, and M. Latif, 2006: Effects of ocean biology on the penetrative radiation in a coupled climate model. J. Climate, 19, 3973-3987, doi:10.1175/JCLI3828.1.

Xu, Q., 1986: The abnormal weather of China for summer 1980 and its relationship with the volcanic eruptions of Mount St. Helens (in Chinese). Acta. Meteor. Sin., 44, 426-432.

Zanchettin, D., C. Timmreck, H.-F. Graf, A. Rubino, S. Lorenz, K. Lohmann, K. Krüger, and J. H. Jungclaus, 2012: Bi-decadal variability excited in the coupled ocean-atmosphere system by strong tropical volcanic eruptions. Climate Dyn., 39, 419-444, doi:10.1007/s00382-011-1167-1.

- O. Bothe, H. F. Graf, S. J. Lorenz, J. Luterbacher, C. Timmreck, and J. H. Jungclaus, 2013: Background conditions influence the decadal climate response to strong volcanic eruptions. J. Geophys. Res. Atmos., 118, 4090-4106, doi:10.1002/ jgrd.50229.

Zhang, D., R. Blender, and K. Fraedrich, 2013: Volcanoes and ENSO in millennium simulations: Global impacts and regional reconstructions in East Asia. Theor. Appl. Climatol., 111, 437-454, doi:10.1007/s00704-012-0670-6.

Zhang, F., and X. Zhang, 1994: The relation between large volcanic eruption in the world and the drought/flood in summer in China. J. Nat. Disasters, 3, 40-46.

Zhou, T., and R.-C. Yu, 2005: Atmospheric water vapor transport associated with typical anomalous summer rainfall patterns in China. J. Geophys. Res., 110, D08104, doi:10.1029/ 2004JD005413.

, and L. Zou, 2010: Understanding the predictability of East Asian summer monsoon from the perspective of land-sea thermal contrast change in AMIP-type simulation. J. Climate, 23, 6009-6026, doi:10.1175/2010JCLI3546.1. 